OPEN ACCESS

Edited by:

Nobuhiro Suzuki,

Okayama University, Japan

Reviewed by:

Massimo Turina

Consiglio Nazionale Delle Ricerche,

Italy

Renato Oliveira Resende

University of Brasilia, Brazil

*Correspondence:

Ralf G. Dietzgen

r.dietzgen@uq.edu.au

${ }^{\dagger}$ Present address: Shirani M. K. Widana Gamage, Department of Botany, University

of Ruhuna, Matara, Sri Lanka

Specialty section: This article was submitted to Virology,

a section of the journa

Frontiers in Microbiology

Received: 30 January 2017

Accepted: 27 March 2017

Published: 11 April 2017

Citation:

Widana Gamage SMK and Dietzgen RG (2017) Intracellular

Localization, Interactions and Functions of Capsicum Chlorosis Virus Proteins.

Front. Microbiol. 8:612. doi: 10.3389/fmicb.2017.00612

\section{Intracellular Localization, Interactions and Functions of Capsicum Chlorosis Virus Proteins}

\author{
Shirani M. K. Widana Gamage ${ }^{\dagger}$ and Ralf G. Dietzgen * \\ Queensland Alliance for Agriculture and Food Innovation, The University of Queensland, St Lucia, QLD, Australia
}

Tospoviruses are among the most devastating viruses of horticultural and field crops. Capsicum chlorosis virus (CaCV) has emerged as an important pathogen of capsicum and tomato in Australia and South-east Asia. Present knowledge about CaCV protein functions in host cells is lacking. We determined intracellular localization and interactions of CaCV proteins by live plant cell imaging to gain insight into the associations of viral proteins during infection. Proteins were transiently expressed as fusions to autofluorescent proteins in leaf epidermal cells of Nicotiana benthamiana and capsicum. All viral proteins localized at least partially in the cell periphery suggestive of cytoplasmic replication and assembly of CaCV. Nucleocapsid ( $N$ ) and non-structural movement (NSm) proteins localized exclusively in the cell periphery, while non-structural suppressor of silencing (NSs) protein and Gc and Gn glycoproteins accumulated in both the cell periphery and the nucleus. Nuclear localization of CaCV Gn and NSs is unique among tospoviruses. We validated nuclear localization of NSs by immunofluorescence in protoplasts. Bimolecular fluorescence complementation showed self-interactions of CaCV N, NSs and NSm, and heterotypic interactions of N with NSs and Gn. All interactions occurred in the cytoplasm, except NSs self-interaction was exclusively nuclear. Interactions of a tospoviral NSs protein with itself and with $\mathrm{N}$ had not been reported previously. Functionally, CaCV NSs showed strong local and systemic RNA silencing suppressor activity and appears to delay short-distance spread of silencing signal. Cell-to-cell movement activity of NSm was demonstrated by trans-complementation of a movement-defective tobamovirus replicon. CaCV NSm localized at plasmodesmata and its transient expression led to the formation of tubular structures that protruded from protoplasts. The $D_{155}$ residue in the $30 \mathrm{~K}$-like movement protein-specific $L x D / N_{50-70} G$ motif of $N S m$ was critical for plasmodesmata localization and movement activity. Compared to other tospoviruses, CaCV proteins have both conserved and unique properties in terms of in planta localization, interactions and protein functions which will effect viral multiplication and movement in host plants.

Keywords: tospovirus, capsicum chlorosis virus, protein intracellular localization, bimolecular fluorescence complementation, cell-to-cell movement, RNA silencing suppression, immunofluorescence, protoplasts 


\section{INTRODUCTION}

Capsicum chlorosis virus was first discovered in capsicum (Capsicum annuum L.) and tomato (Solanum lycopersicum L.) crops in Queensland, Australia in 1999 (McMichael et al., 2002). Subsequently, CaCV was recorded in China, India, Taiwan, and Thailand from capsicum, groundnut and tomato crops and ornamental plants (Knierim et al., 2006; Chen C. et al., 2007; Chen K. et al., 2007; Kunkalikar et al., 2007). Due to a lack of natural resistance in commercial cultivars and inefficient control of transmitting thrips vectors, $\mathrm{CaCV}$ is of growing concern to horticultural industries.

Taxonomically, $\mathrm{CaCV}$ is considered as a tentative species in the genus Tospovirus, the only genus in the family Bunyaviridae representing plant-infecting viruses (Plyusnin et al., 2011). The genome of $\mathrm{CaCV}$ has the typical tospovirus genome structure consisting of three linear RNA segments with negative or ambisense coding polarity (Knierim et al., 2006; Zheng et al., 2011; Widana Gamage et al., 2015). The RNA segments are named as large (L), medium (M), and small (S) based on size. L RNA contains a single open reading frame (ORF), which codes for an RNA-dependent RNA polymerase (RdRP) (de Haan et al., 1991). M RNA contains two ORFs separated by an intergenic region (IGR), which code for non-structural movement (NSm) and precursor of glycoproteins (GP) (Kormelink et al., 1992). GP is post-translationally cleaved into $\mathrm{Gn}$ and Gc glycoproteins (Adkins et al., 1996). S RNA also contains two ORFs separated by an IGR, which code for non-structural suppressor of silencing (NSs) and nucleocapsid (N) proteins (de Haan et al., 1990). The virion core contains ribonucleoproteins (RNPs) consisting of RNA segments tightly associated with N protein (Ie, 1971; Kormelink, 2011; Li et al., 2014). Encapsidated tospovirus RNA genome segments with several copies of RdRP are collectively bound by a lipid envelope, which is decorated by Gn and Gc glycoprotein projections (van Poelwuk et al., 1993; Kikkert et al., 1999).

Tomato spotted wilt virus (TSWV) is the best-studied tospovirus. Molecular biology of TSWV infection has been studied using various model plant and animal systems (Kikkert et al., 2001; Lewandowski and Adkins, 2005; Snippe et al., 2005, 2007a,b; Paape et al., 2006; Ribeiro et al., 2008, 2009). TSWV replication, transcription and particle assembly takes place in the cytoplasm (Ie, 1971; Goldbach and Peters, 1996; Kikkert et al., 1999). In host plants, viral RNPs in association with NSm are transported from initially infected cells to neighboring cells through plasmodesmata (PD), assisting progression of the infection (Storms et al., 1995; Soellick et al., 2000). Recently, molecular interactions of viral and host proteins have been reported for TSWV and several other tospoviruses (Paape et al., 2006; Feng et al., 2013, 2016; Singh and Savithri, 2015). These findings point to significant complexity in the tospovirus infection process and unexplored unique characteristics for some tospovirus proteins beyond TSWV.

Although $\mathrm{CaCV}$ has been identified more than a decade ago, it has not been widely studied. Hence, to understand the molecular basis of $\mathrm{CaCV}$ infection process while constrained by the lack of a reverse genetics system for tospoviruses, we determined intracellular localization and interactions of its proteins and discuss these data in the context of viral replication, particle assembly, and intercellular movement. Furthermore, we have experimentally demonstrated the functions of $\mathrm{CaCV}$ non-structural proteins NSm and NSs that are involved in cellto-cell movement and RNA silencing suppression, respectively.

\section{MATERIALS AND METHODS}

\section{Plasmid Constructs}

All CaCV ORFs except that coding for RdRP were amplified by reverse transcription polymerase chain reaction (RT-PCR) and cloned into plant expression destination vectors using Gateway $^{\mathrm{TM}}$ technology. Briefly, cDNA was synthesized from total RNA extracted from CaCV (QLD-3432)-infected capsicum using SuperScript III First-Strand Synthesis SuperMix (Life Technologies) and random primers. CaCV ORFs encoding N, NSs, NSm, Gc, and Gn proteins were amplified with gene-specific primers using Phusion High Fidelity polymerase (Finnzymes). To facilitate subsequent Gateway cloning, primer sequences were flanked with $a t t B$ recombination sites at $5^{\prime}$ ends. PCR amplicons were gel-purified (Wizard gel purification kit, Promega), cloned into pDONR221 using BP Clonase II Enzyme Mix (Life Technologies) and transformed into chemically competent Omnimax Escherichia coli (Life Technologies) using heat shock method. Recombinant colonies were selected on Luria-Bertani (LB) agar containing $50 \mathrm{mg} / \mathrm{L}$ kanamycin. Plasmid DNA was extracted from recombinant bacterial cultures using GeneJet plasmid purification kit (Thermo Fisher Scientific) and sequenced. Sequence-validated entry clones were recombined into C-series of pSITE and pSITE II destination vectors (Chakrabarty et al., 2007; Martin et al., 2009) as fusions to green fluorescent protein (GFP), red fluorescent protein (RFP) and/or Flag peptide for localization studies and to yellow fluorescent protein (YFP) fragments for bimolecular fluorescence complementation (BiFC) assays using LR Clonase II Enzyme Mix (Life Technologies). Recombinant pSITE vectors carrying CaCV ORFs were confirmed by colony PCR (AmpliTaq GoldFast PCR, Applied Biosystems, Thermo Fisher Scientific) and were individually transformed into Agrobacterium tumefaciens LBA 4404.

\section{Agroinfiltration and Live Cell Imaging}

$\mathrm{CaCV}$ fusion proteins were transiently expressed in plants using leaf agroinfiltration to determine intracellular localization and interactions. Agrobacterium suspensions at $0.7-0.8$ optical density $\left(\mathrm{OD}_{600}\right)$ were infiltrated into Nicotiana benthamiana epidermal leaf cells as previously described (Tsai et al., 2005). For localization studies, $N$. benthamiana wild-type or RFP fused to histone 2B (RFP-H2B) transgenic marker plants, or capsicum cv. Yolo Wonder were used, whereas for BiFC protein-protein interaction assays, cyan fluorescent protein fused to histone 2B (CFP-H2B) transgenic marker plants were used (Martin et al., 2009). To visualize intracellular structures, mCherry-ER (endoplasmic reticulum) and mCherry-Golgi marker plasmids (Nelson et al., 2007) transformed into A. tumefaciens LBA 4404 
were co-infiltrated with cultures carrying $\mathrm{CaCV}$ fusion protein constructs. Callose deposits at PD were stained with $0.033 \mathrm{mg} / \mathrm{mL}$ aniline blue fluorochrome (Biosupplies, Australia) by infiltration into leaves $30 \mathrm{~min}$ before visualization. For BiFC assays all viral proteins were expressed as C-terminal fusions to the amino- or carboxy-terminal portions of YFP using pSITE-BiFC-nEYFP and pSITE-BiFC-cEYFP vectors (Martin et al., 2009). Leaf sections were viewed using Zeiss LSM-700 (Carl Zeiss) confocal laser scanning microscope (CLSM) at 2 days post infiltration (dpi). Images were acquired as CZI files and processed using Zen Lite 2012 and ImageJ software (Schneider et al., 2012).

\section{Protoplast Isolation and Imaging of NSm Expression}

Protoplasts were isolated from $N$. benthamiana leaves according to a protocol kindly provided by Dr. Richard Kormelink (Wageningen University, The Netherlands) with slight modifications. Briefly, leaves from greenhouse-grown, 4-weeks old $N$. benthamiana were co-agroinfiltrated with pSITE constructs carrying RFP-NSm and free eGFP (Chakrabarty et al., 2007). Infiltrated plants were incubated under constant light for $22 \mathrm{~h}$ at room temperature and protoplasts were isolated from $2 \mathrm{~g}$ of infiltrated tissue. Harvested leaves were surface-sterilized by immersing in $70 \%$ ethanol for $10 \mathrm{~s}$, followed by three washes in sterile MilliQ water. After removal of mid rib, leaves were sliced into 1-2 $\mathrm{mm}$ strips and macerated overnight in the dark at $4^{\circ} \mathrm{C}$ in $50 \mathrm{~mL}$ of an enzyme solution containing $0.6 \mathrm{~g}$ cellulase (Onozuka R-10), $30 \mathrm{mg}$ Macerozyme R-10 (PhytoTechnology Laboratories), and $4.55 \mathrm{~g}$ mannitol. Released protoplasts were filtered through a nylon cell strainer with $70 \mu \mathrm{m}$ diameter pores (Falcon, Corning brand) and collected on a $20 \%$ sucrose cushion after centrifugation for $10 \mathrm{~min}$ at $100 \times \mathrm{g}$. Protoplasts were collected from the interface and resuspended in $0.6 \mathrm{M}$ mannitol. The suspension was centrifuged again to collect protoplasts and resuspended in mannitol solution to adjust volume and concentration. Protoplast viability was tested by staining with $1 \%$ Evan's Blue (Sigma-Aldrich). Viable protoplasts were counted using a haemocytometer (Weber, England) using a light microscope with $10 \times 10$ magnification (Olympus BH2). Protoplast suspension was spotted on poly-L-lysine coated glass slides (Sigma-Aldrich) and incubated with constant light at room temperature. Protoplasts were observed with Zeiss LSM-700 (Carl Zeiss) CLSM starting from 4 to $8 \mathrm{~h}$ of incubation. Images were acquired using $40 \mathrm{x}$ lens as CZI files and processed using Zen Lite 2012 and ImageJ software (Schneider et al., 2012).

\section{Immunofluorescent Detection of NSs Protein in Protoplasts}

Nuclear localization of NSs was validated by immunofluorescence microscopy. Protoplasts were isolated from RFP-H2B transgenic $N$. benthamiana leaf tissue that transiently expressed Flag-tagged CaCV NSs $22 \mathrm{~h}$ after agroinfiltration. As control, protoplasts were isolated from plants agroinfiltrated with pSITE-Flag vector. Protoplast suspension was spotted on poly-L-lysine coated glass slides. NSs was detected using a mouse monoclonal antibody (MAb) (1:1000) directed against NSs of watermelon silver mottle virus (WSMoV) serogroup viruses (Chen et al., 2006) following a previously described protocol with slight modifications (Hibi et al., 1975; Kikkert et al., 1997). A mouse IgG1 antibody (1:1000) was used as non-specific antibody control. Antigen-antibody complexes were detected by goat anti-mouse IgG $(\mathrm{H}+\mathrm{L})$ conjugated with Alexa Fluor 488 (1:300, Life Technologies). Slides were examined with a Zeiss LSM-700 (Carl Zeiss) CLSM.

\section{Virus Movement Trans-complementation}

Cell-to-cell movement function of NSm was demonstrated using a turnip vein clearing virus (TVCV)-based movement transcomplementation system (Mann et al., 2016) derived from a pro-vector system consisting of three modules; $5^{\prime}$ module pICH17388: TVCV RdRP and TVCV P30 MP; $3^{\prime}$ module pICH7410: GFP reporter and tobacco mosaic virus (TMV) non-translated region and pICH14011: integrase (Marillonnet et al., 2004, 2005; Giritch et al., 2006). This system was modified to be movement defective by introducing a mutation in P30 MP (Mann et al., 2016). NSm or NSm mutant ( $\Delta \mathrm{NSm})$ constructs fused to RFP were co-expressed with movement-defective TVCV system by agroinfiltration into $N$. benthamiana epidermal leaf cells following the method described by Mann et al. (2016). Functional and mutated TVCV P30 (Mann et al., 2016) and TSWV NSm (QLD-1255 isolate) fused to RFP were used as positive controls. Empty RFP vector was used as negative control. Images were acquired 7 days after agroinfiltration using a Zeiss LSM-700 (Carl Zeiss) CLSM. At least 50 GFP foci per construct per experiment were observed and cells expressing GFP were counted. The efficiency of cell-to-cell movement was estimated by counting number of adjacent cells expressing GFP.

\section{Generation of NSm Mutants}

Sequence-validated $\mathrm{CaCV}$ and TSWV NSm entry clones were used as templates to generate movement-defective NSm $(\triangle \mathrm{NSm})$ constructs using $\mathrm{Q}^{\circledR}{ }^{\circledR}$ Site-Directed Mutagenesis kit (New England Biolabs) following manufacturer's instructions. Primers for mutagenesis were designed using NEBaseChanger (New England Biolabs) online following the recommendations for substitution primers. Mutations in entry clones were confirmed by sequencing. Mutants were recombined into pSITERFP-C1 vector and transformed into A. tumefaciens LBA 4404.

\section{Suppression of gfp Silencing}

Entry clones of $\mathrm{CaCV}$ NSs in pDONR221 were recombined into pSITE-Flag-C1 destination vector (Chakrabarty et al., 2007). Similarly, a recombinant pSITE vector carrying FlagTSWV NSs was constructed from TSWV QLD-1255 isolate as positive control. Recombinant vectors were transformed into A. tumefaciens LBA4404. Agrobacteria harboring recombinant pBIN vector carrying mGFP5-ER gene were used as inducer of RNA silencing. Agrobacteria carrying Flag-NSs and mGFP5-ER constructs were co-infiltrated with 1:1 ratio into GFP-expressing N. benthamiana line 16c (Ruiz et al., 1998). Local and systemic silencing assays were independently performed at least three times. GFP fluorescence was monitored at 3 and $7 \mathrm{dpi}$ for local silencing and 14 and $21 \mathrm{dpi}$ for systemic silencing using 
a blue light (HL32T Dark Reader hand lamp, Clare Chemicals Research). Images were acquired using Canon EOS 600D digital camera equipped with a blue light filter. Formation of red zone surrounding infiltrated patches was observed using a long wavelength Black Ray model B 100AP UV lamp (UVP, Upland, CA, USA) at $365 \mathrm{~nm}$. Images were acquired using Canon EOS 450D camera equipped with a GFP filter.

\section{Protein Expression Analysis}

Transient expression of two selected viral proteins fused to GFP, N, and NSs following agroinfiltration was validated by western blot. Soluble proteins from agroinfiltrated leaf tissues at 2 dpi (for localization assay) or 3 dpi (suppression of RNA silencing assay) were extracted in protein sample buffer (Laemmli, 1970) and separated on a SDS-12\% polyacrylamide gel. Proteins were transferred to PVDF membrane (Millipore) and detected using mouse anti-GFP antibodies (1:1000, Roche Life Science) or mouse monoclonal anti-Flag M2 clone 2 antibody (1:2000, Sigma-Aldrich) followed by rabbit anti-mouse IgG horseradish peroxidase conjugate $(1: 25,000)$, Pierce ECL Plus chemiluminescent substrate, and exposure to $\mathrm{x}$-ray film (Fujifilm). Protein sizes were estimated using pre-stained Page Ruler protein ladder (Thermo Fisher Scientific).

\section{In silico Sequence Analyses}

Deduced amino acid sequences of $\mathrm{CaCV}$ proteins were analyzed for potential nuclear localization (import) and nuclear export signals using cNLS Mapper (Kosugi et al., 2009) and NetNES 1.1 server (La Cour et al., 2004). Secondary structure prediction and alignment of CaCV (KM589494), TSWV NSm (QLD-1255, unpublished), TMV P30 (NC_001367.1), and TVCV P30 (U03387) were carried out using PROMALS3D online (Pei and Grishin, 2014). NSm sequences were analyzed for predicted coiled-coil domains using an online server (McDonnell et al., 2006).

\section{RESULTS}

\section{Intracellular Localization of CaCV Proteins In planta}

To determine intracellular localization of viral proteins, we transiently expressed all individual $\mathrm{CaCV}$ proteins except RdRP as fusions to the C-terminus of GFP and visualized fusion protein accumulation using CLSM. Expression of GFP-N and GFP-NSs fusion proteins was confirmed by western blot at 3 dpi (data not shown). Experimental evidence for expression of all GFP fusion proteins is provided by confocal microscopy showing altered intracellular localization compared to free GFP (Figure 1).

In $N$. benthamiana, all ectopically expressed $\mathrm{CaCV}$ proteins localized to the cell periphery near ER membranes (Figure 1 and Supplementary Figure 1). Free GFP could be seen in both the cell periphery and in the nucleus. GFP:N formed varying sized aggregates in the cell periphery and perinuclear region. GFP:NSs showed slightly punctate distribution in the

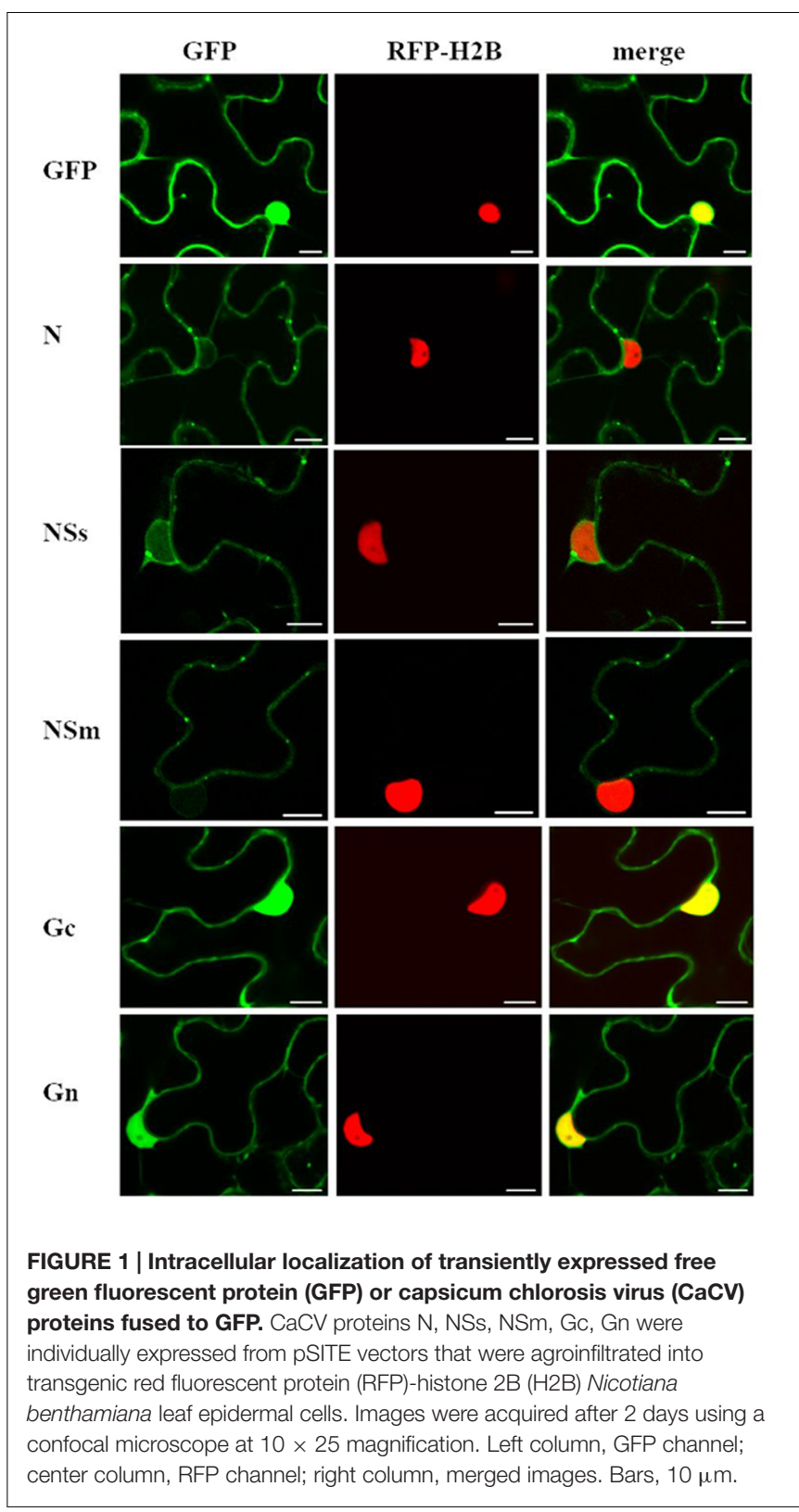

cell periphery. In addition, NSs also accumulated in the nucleus in agreement with a predicted moderately strong bipartite NLS (cNLS mapper score 4.1). However, TSWV NSs that is thought to be cytoplasmic yielded a similar cNLS score of 4.4. GFP:NSs was observed in $86 \%$ of nuclei in three independent experiments with a total of 50 nuclei observed in each experiment. Since accumulation of NSs in the nucleus was unexpected considering previous localization studies of NSs of other tospoviruses, we captured three-dimensional Z-stack images at various depths to validate NSs nuclear localization (Supplementary Figure 2). Composite images confirmed that NSs indeed accumulated inside the nucleus, but not in the nucleolus that appeared as a dark spot (Supplementary Figure 2-V). GFP:NSm showed discontinuous punctate spots in the cell periphery. GFP:Gc and GFP:Gn 
showed similar localization profiles with smooth distribution in the cell periphery and also accumulation in the nucleus as supported by predicted canonical NLSs. The cNLS mapper software predicted two monopartite NLSs (scores 5.5 and 4.0) and two bipartite NLSs (scores 7.6 and 4.1) for Gc and two bipartite NLSs (score 4.1) for Gn. Twenty nuclei each observed in three independent experiments showed 100\% GFP:Gc and GFP:Gn nuclear localization.

Localization of $\mathrm{CaCV}$ proteins was validated in wild-type $N$. benthamiana and in capsicum plants (Supplementary Figures 1A,B), both susceptible host plant species for $\mathrm{CaCV}$. ER membranes were visualized as an internal marker by co-expression of ER-targeted mCherry RFP. All CaCV proteins showed a similar localization pattern as that in transgenic RFP-H2B N. benthamiana cells (compare Figure $\mathbf{1}$ and Supplementary Figure 1). GFP:NSs was consistently observed in $>80 \%$ of nuclei in cells of wild-type and transgenic $N$. benthamiana and wild-type capsicum.

\section{CaCV NSs Accumulates in the Nucleus}

We validated nuclear accumulation of $\mathrm{CaCV}$ NSs by immunofluorescence using a MAb directed against a common epitope in the NSs of tospovirus members of the WSMoV serogroup (Chen et al., 2006) in protoplasts of RFP-H2B nuclear marker $N$. benthamiana that transiently expressed CaCV NSs.
Controls used in this experiment to validate specific MAb binding to NSs included agroinfiltrated empty vector and a mouse IgG1 polyclonal antibody for detection. NSs localization was determined by indirect immunofluorescence. Bright green fluorescence of Alexa Fluor 488 conjugate overlapped with red (RFP) nuclei of protoplasts expressing NSs (Figure 2). In contrast, we did not detect any fluorescence in the nuclei or the cytoplasm of control protoplasts or when mouse IgG was used for detection. Nuclear localization of NSs was seen in $>95 \%$ of a total of 50 nuclei observed in two independent experiments based on the number of green fluorescing nuclei.

\section{Golgi Complex Association of CaCV Glycoproteins}

We tested the potential association of individual $\mathrm{CaCV}$ glycoproteins with the Golgi complex by transient co-expression of GFP:Gc and/or GFP:Gn with mCherry-Golgi marker (Nelson et al., 2007). With this marker Golgi stacks could be seen as round shaped disks in the cytoplasm and along the cell periphery (Figure 3). In addition mCherry-Golgi weakly labeled the ER. Both GFP:Gc and GFP:Gn appeared largely non-Golgi associated, however, some orange colored spots appeared with GFP:Gn due to co-localization of GFP and mCherry fusion proteins in merged images (Figure 3). Light

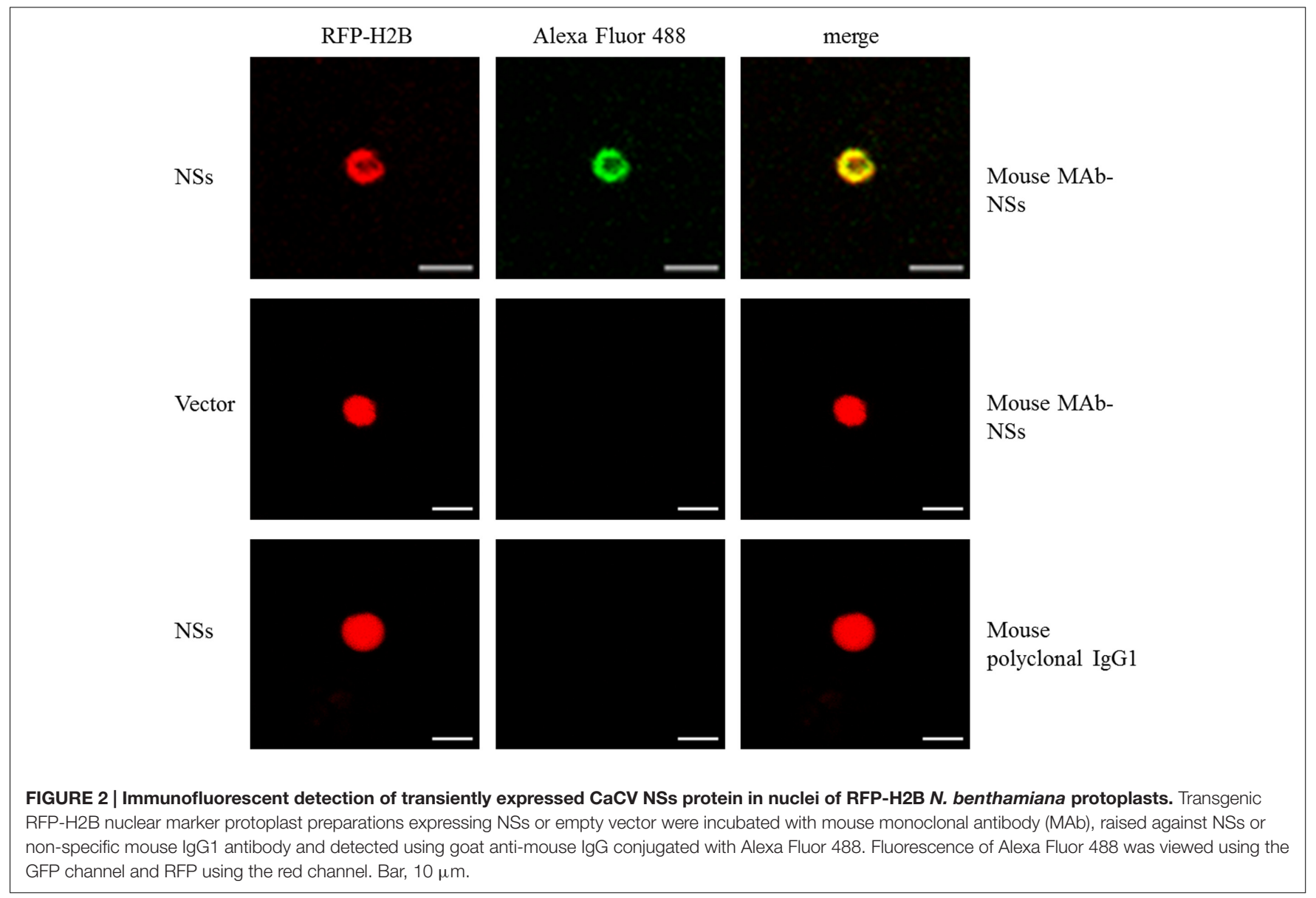




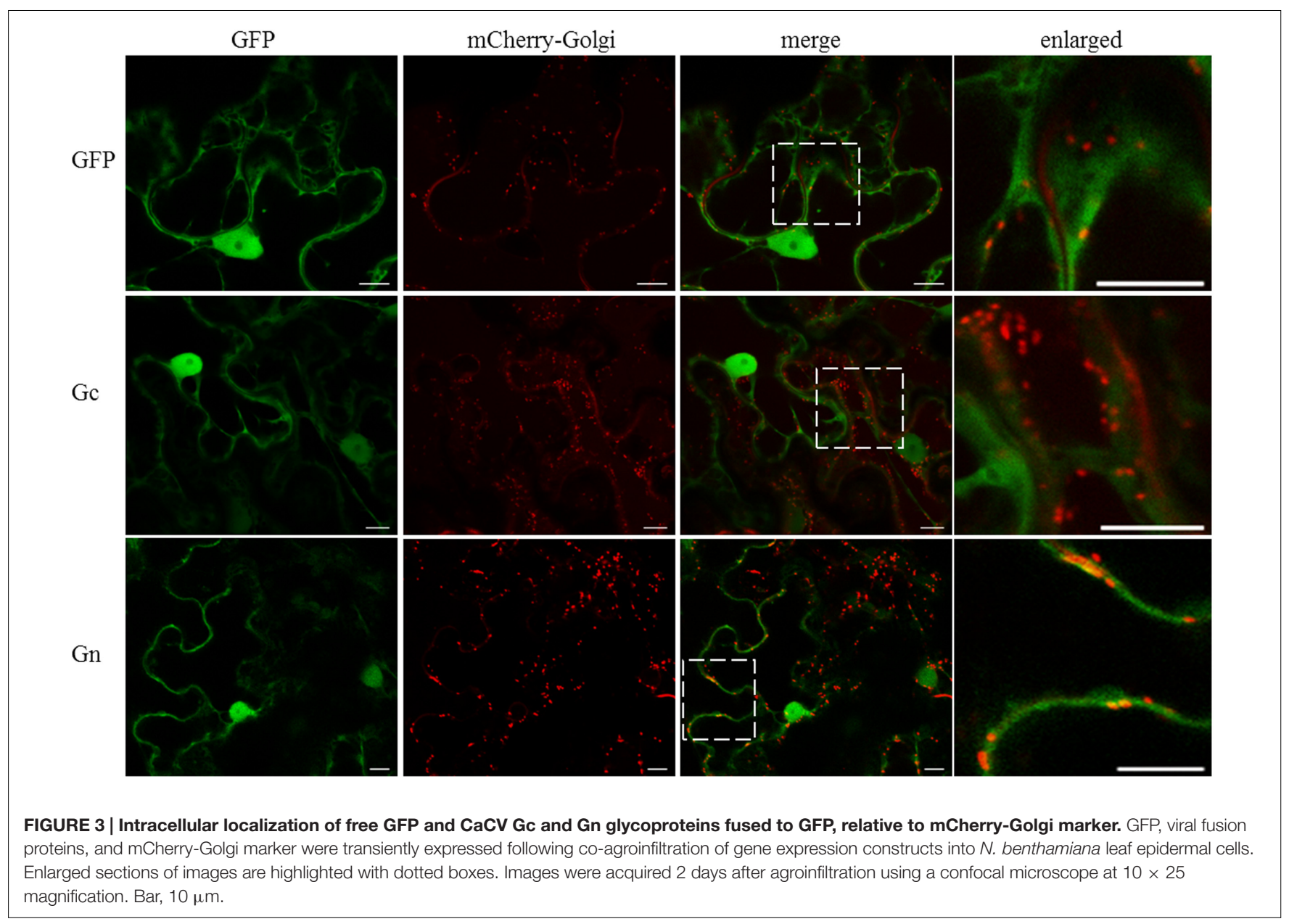

orange colored spots were also visible with free GFP control and GFP:Gc co-localized with mCherry-Golgi. When enlarged, co-localization spots of $\mathrm{G}$ n could be more clearly distinguished with distinct orange color compared to free GFP and Gc spots. Therefore, it appears that Gn, but not Gc localizes infrequently within Golgi stacks. To determine whether co-expression of both glycoproteins affects their localization, we transiently co-expressed the glycoproteins as GFP and/or Flag fusions. Co-expression of Gc and Gn did not show an altered localization profile compared to the individual fusion proteins (data not shown).

\section{CaCV NSm Protein Localizes at Plasmodesmata}

Based on well-studied NSm proteins of other tospoviruses, we predicted that $\mathrm{CaCV} \mathrm{NSm}$ is involved in viral cell-tocell movement. This hypothesis is supported by NSm protein localization at PD as evidenced by discontinues punctate spots in the cell periphery (Figure $\mathbf{1}$ and Supplementary Figure 1). We validated PD localization in N. benthamiana cells transiently expressing CaCV GFP:NSm by confocal microscopy at $2 \mathrm{dpi}$ relative to the location of aniline blue fluorochrome which stains callose-rich regions at PD. GFP:NSm punctate spots on the cell periphery showed perfect co-localization with aniline blue dye indicating PD localization of $\mathrm{CaCV} \mathrm{NSm}$ (Figure 4).

\section{Intracellular Interactions of CaCV Proteins In planta}

We used BiFC to determine $\mathrm{CaCV}$ protein-protein interactions and localization in all pair-wise combinations. Individual proteins were transiently expressed in transgenic CFP-H2B plants as fusions to the C-terminus of YFP $\mathrm{n}$ - and c-terminal fragments. Glutathione-S-transferase (GST) was used as non-binding control. BiFC interactions were seen as restoration of YFP fluorescence (Figure 5). We observed homotypic (self) interactions of $\mathrm{N}, \mathrm{NSs}$, and NSm. N-N interactions appeared as abundant aggregates in diverse sizes in the cytoplasm and perinuclear region, similar to N protein localization (see Figure 1 and Supplementary Figure 1). NSs self-interaction was observed exclusively inside the nucleus. NSm homotypic interactions were seen along the cell periphery as discontinuous punctate spots. We also detected heterotypic interactions involving $\mathrm{N}$ protein in the cytoplasm. $\mathrm{N}$ interacted with NSs in both orientations and with Gn only in the Gn-N orientation (Figure 5). No other interactions were observed by BiFC in either orientation. None 


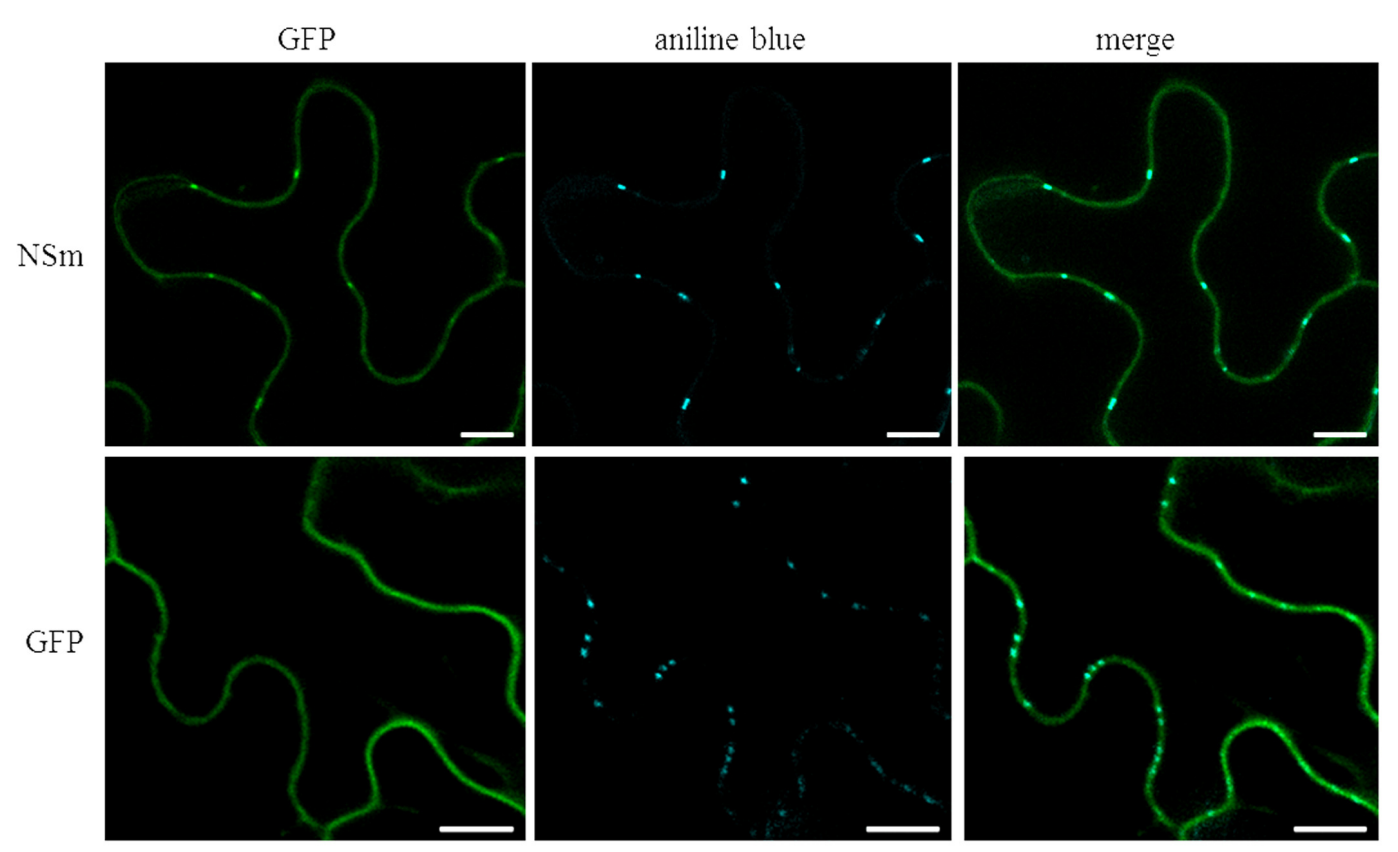

FIGURE 4 | Co-localization of CaCV NSm protein with plasmodesmata (PD) marker dye, aniline blue. N. benthamiana leaves transiently expressing GFP:NSm or free GFP were infiltrated with aniline blue fluorochrome solution. Images were taken 2 days after agroinfiltration using a confocal microscope at $10 \times 25$ magnification. Aniline blue was false color imaged as cyan to increase contrast. Bars, $10 \mu \mathrm{m}$.

of the CaCV proteins showed any interaction with GST in either orientation (Figure 5 and data not shown).

\section{CaCV and TSWV NSm \\ Trans-complement Cell-to-Cell Movement of a Movement-defective Tobamovirus Replicon}

We provide experimental evidence that both $\mathrm{CaCV}$ and TSWV NSm function as cell-to-cell movement proteins in a tobamovirus replicon trans-complementation assay. NSm proteins fused to RFP (so their expression could be verified by CLSM) were transiently expressed in $N$. benthamiana epidermal leaf cells together with a movement-defective TVCV replicon (TVCV $\triangle \mathrm{MP}$ ) composed of three modules; defective movement module, GFP reporter module, and integrase module. Complementation of TVCV $\triangle \mathrm{MP}$ movement was observed by confocal microscopy as spread of the GFP reporter replicon across five or more adjacent cells. Empty RFP vector was used as negative control and homologous P30:RFP as positive control.

Co-expression of TVCV $\triangle \mathrm{MP}$ modules with $\mathrm{CaCV}$ or TSWV NSm showed many GFP-expressing cell clusters comprising five cells or more, similar to the TVCV P30 control at $7 \mathrm{dpi}$ (Figure 6A). By contrast, when TVCV $\triangle \mathrm{MP}$ was co-expressed with empty RFP vector, GFP expression was limited to single cells (Figure 6C). These data provide evidence that tospovirus NSm was able to facilitate cell-to-cell movement of a movement-defective TVCV replicon. However, cell-to-cell movement pattern of TVCV $\triangle \mathrm{MP}$ replicon appeared different when complemented by $\mathrm{CaCV}$ NSm versus TSWV NSm. CaCV
NSm trans-complemented TVCV $\triangle \mathrm{MP}$ movement radially in all directions generating large clusters of cells similar to TVCV P30. On the other hand, TSWV NSm trans-complementation often led to movement in a single direction generating a line of GFP-expressing cells and rarely led to radial clusters (data not shown). Efficiencies of movement trans-complementation by TVCV P30, CaCV NSm, and TSWV NSm were 65, 51, and 36\%, respectively (Table $\mathbf{1}$ ).

Secondary structure prediction showed tospovirus MPs contain the conserved $30 \mathrm{~K}$ protein-specific $\mathrm{LxD} / \mathrm{N}_{50-70} \mathrm{G}$ motif. To confirm specificity of NSm movement function, we generated mutant RFP-NSm (RFP- $\triangle \mathrm{NSm}$ ) constructs by replacing $\mathrm{D}$ (aspartic acid) residue with $\mathrm{A}$ (alanine) in the conserved motif. At 7 dpi, TVCV $\triangle \mathrm{MP}$ co-expressed with $\mathrm{CaCV}$ or TSWV RFP- $\triangle$ NSm or $\triangle$ P30-RFP showed limited GFP expression confined to majority of 1-2 isolated cells similar to vector control (Figure 6B and Table 1). Taken together these data provide strong evidence that $\mathrm{CaCV}$ and TSWV NSm possess cell-to-cell movement activity that was able to trans-complement movement of a dysfunctional tobamovirus replicon, and mutation of the essential $\mathrm{D}$ residue in the $\mathrm{LxD} / \mathrm{N}_{50-70} \mathrm{G}$ motif specifically eliminated this movement activity.

To determine whether substitution of $\mathrm{D}$ residue in $\mathrm{LxD} / \mathrm{N}_{50-70} \mathrm{G}$ motif also effects PD localization, $N$. benthamiana leaves transiently expressing CaCV RFP-NSm or $-\triangle \mathrm{NSm}$ were infiltrated with aniline blue to stain callose at PD. Wild-type RFP-NSm localized to the cell periphery in punctate spots (Figure 7) similar to GFP-NSm (Figure 1), whereas RFP- $\triangle N S m$ was instead smoothly distributed along the cell periphery (Figure 7). RFP-NSm aggregates perfectly overlapped with 


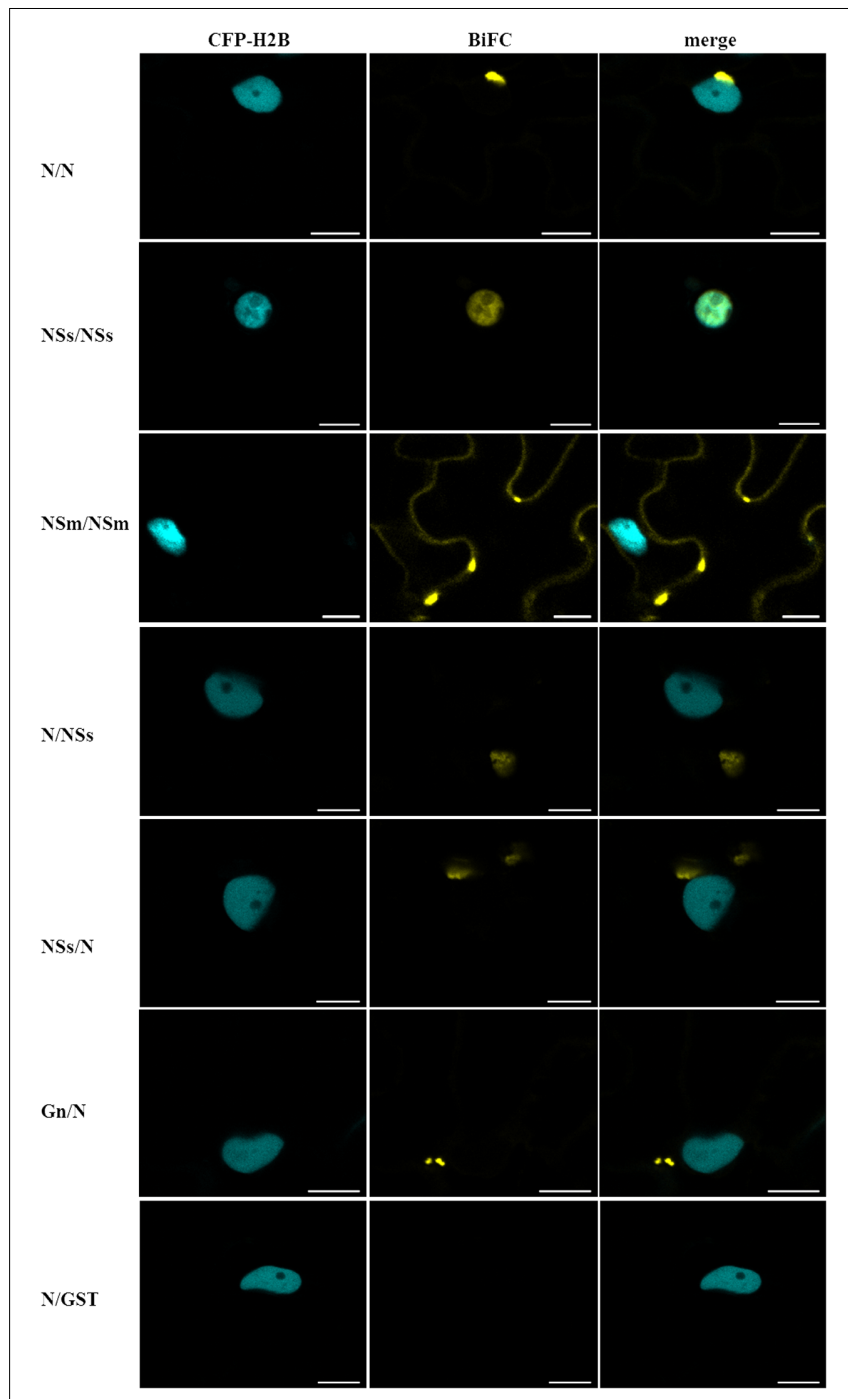

FIGURE 5 | Bimolecular fluorescence complementation (BiFC) to identify $\mathbf{C a C V}$ protein-protein interactions. Viral proteins were transiently expressed as fusions to yellow fluorescent protein (YFP) N- or C-terminal fragments in pSITE-BiFC vectors following agroinfiltration into transgenic $N$. benthamiana expressing cyan fluorescent protein fused to histone $2 \mathrm{~B}$ (CFP-H2B). Images of leaf epidermal cells were acquired after 2 days using a confocal microscope at $10 \times 25$ magnification. YFP fragments in interacting protein combinations are indicated in the order $n-Y F P / c-Y F P$.

Glutathione-S-transferase (GST) was used as non-binding control in all combinations, but only one example is shown. Bars, $10 \mu \mathrm{m}$.

aniline blue spots indicating PD localization. Collectively, these data confirm that mutation of $\mathrm{D}_{155}$ residue in $\mathrm{CaCV}$ $\mathrm{LxD} / \mathrm{N}_{50-70} \mathrm{G}$ motif eliminates PD localization and cell-to-cell movement activity of NSm protein, suggesting that $\mathrm{CaCV} \mathrm{NSm}$ is a $30 \mathrm{~K}$-like viral movement protein.

\section{CaCV NSm Forms Tubular Structures Protruding from Protoplasts}

We observed tubule-like projections on the surface of protoplasts that had been isolated from $N$. benthamiana leaves that transiently expressed RFP-NSm (CaCV or TSWV). TSWV NSm was used as a positive control and free GFP expression was used to highlight location of cellular structures, ER, and nucleus. Tubular structures appeared after $5 \mathrm{~h}$ incubation of protoplast suspensions on poly-L-lysine coated slides (Figure 8). Often, tubular structures looked like short projections, but occasionally longer tubules were seen. These results provide evidence that $\mathrm{CaCV}$ NSm, like its TSWV counterpart is capable of forming tubular structures, which may facilitate cell-to-cell movement of the virus in infected plant cells.

\section{CaCV NSs Suppresses gfp Silencing Locally and Systemically}

We demonstrate that $\mathrm{CaCV}$ NSs functions as a suppressor of RNA silencing using well-established GFP reporter assays (Johansen and Carrington, 2001). CaCV NSs was co-expressed with GFP silencing inducer, mGFP5-ER in transgenic $N$. benthamiana line 16c, which constitutively expresses mGFP5-ER. The known suppressor TSWV NSs and pSITE-Flag vector were used as positive and negative controls, respectively. Transient expression of Flag-tagged NSs proteins was confirmed by western blot at 3 dpi (data not shown). Co-expression of $\mathrm{CaCV}$ NSs with GFP reporter gene enhanced visible GFP expression at 3-4 days after infiltration locally in the infiltrated leaf patch (Figure 9A). GFP fluorescence was strong and comparable to that seen with TSWV NSs. Leaf patches infiltrated with empty vector showed significantly diminished GFP fluorescence, indicating silencing of the reporter gene. This data confirms that $\mathrm{CaCV}$ NSs is a local RNA silencing suppressor. GFP fluorescence in the $\mathrm{CaCV}$ NSs expressing patch remained bright at 7 dpi, while $g f p$ reporter in TSWV NSs and vector leaf patches were silenced (Figure 9B). To investigate if NSs has an effect on the short-distance spread of $g f p$ silencing, the formation of an indicative 'red zone' was monitored at 7 dpi. Wide red zones were clearly visible surrounding the leaf patches expressing TSWV NSs and vector (Figure 9C). At that time point, local GFP expression in the infiltrated leaf patch had ceased/was silenced (TSWV NSs silencing suppression was overcome), while systemic movement of the silencing signal had been initiated. By contrast, a narrow red zone was visible surrounding the leaf patch expressing $\mathrm{CaCV}$ NSs. This data indicates that $\mathrm{CaCV}$ NSs delays or interferes with the short-distance spread of the RNA silencing signal.

To investigate systemic silencing activity of CaCV NSs, GFP fluorescence in upper non-infiltrated leaves was monitored in $N$. benthamiana line $16 \mathrm{c}$ plants that had been agroinfiltrated with NSs constructs or empty vector plus mGFP5-ER. Leaves were considered systemically silenced if complete or partial chlorophyll auto fluorescence (red) was observed whereas leaves were considered non-silenced/ suppressed if GFP fluorescence resembled that of the mock (buffer-infiltrated) control plants. At $21 \mathrm{dpi}$, in two independent experiments all plants infiltrated with empty vector and 


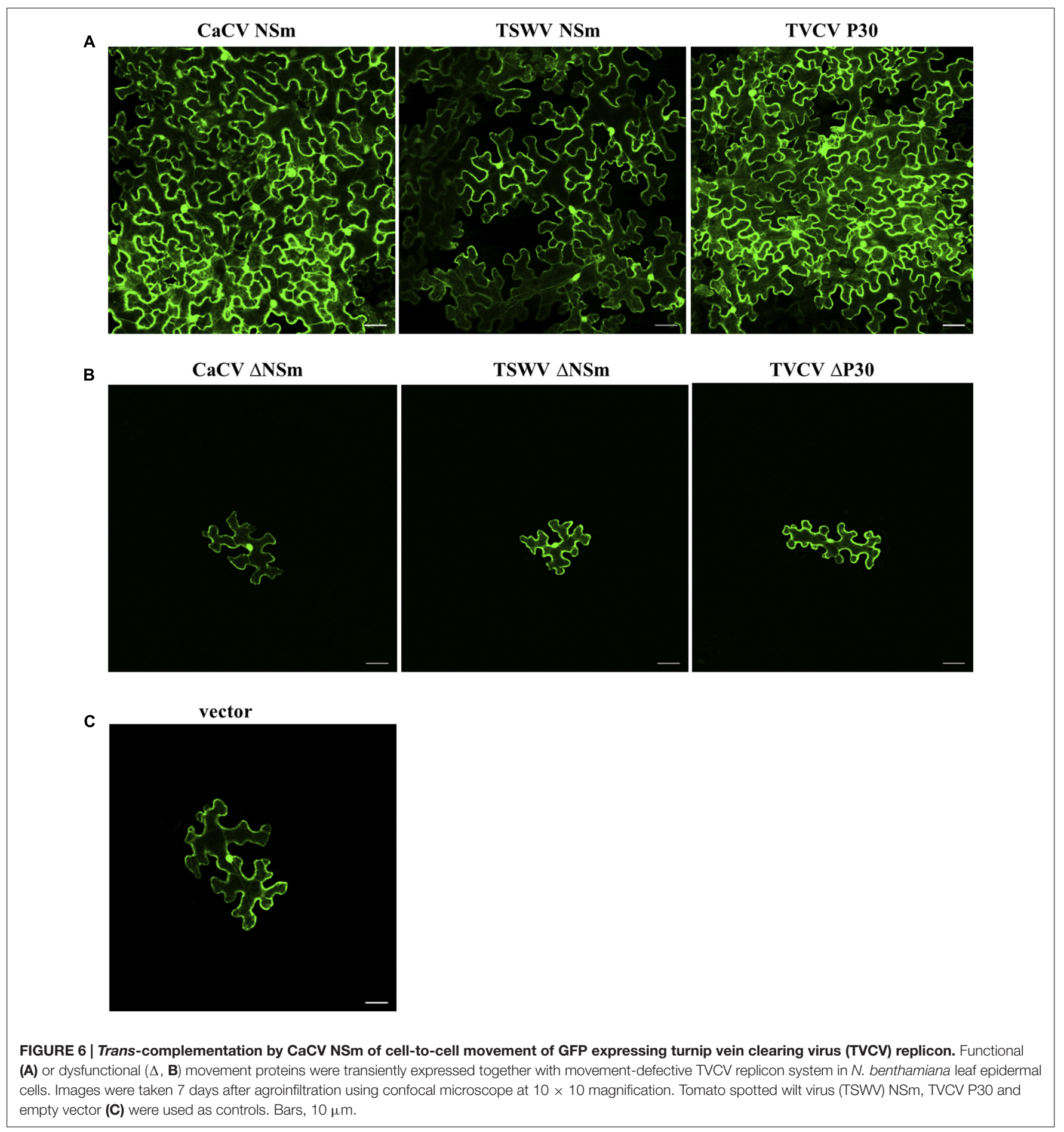

mGFP5-ER constructs (16/16) showed GFP silencing in upper non-infiltrated leaves (Figure 9D), whereas in most plants that were agroinfiltrated with constructs expressing mGFP5-ER plus CaCV NSs (15/16) or TSWV NSs (14/16) systemic silencing was suppressed and GFP expression was observed (Figures 9E,F). This data indicates that CaCV NSs suppresses GFP silencing systemically with a similar efficiency as TSWV NSs.

\section{DISCUSSION}

Tomato spotted wilt virus is the best-studied tospovirus in terms of particle morphology, genome organization, replication and transcription strategies and therefore TSWV represents the prototype tospovirus (Kormelink et al., 2011). However, recent studies of TSWV and other tospoviruses have provided evidence for novel or previously unexplored tospovirus features. 
TABLE 1 | Cell-to-cell movement trans-complementation of turnip vein clearing virus (TVCV) movement-defective replicon (TVCV $\triangle$ MP) by functional and dysfunctional $(\Delta)$ tospovirus NSm proteins.

\begin{tabular}{cccccc}
\hline TVCV $\Delta M P+$ & $\begin{array}{c}1-2 \\
\text { cells }\end{array}$ & $\begin{array}{c}3-4 \\
\text { cells }\end{array}$ & $\begin{array}{c}\geq 5 \\
\text { cells }\end{array}$ & $\begin{array}{c}\text { Total foci } \\
\text { counted }\end{array}$ & $\begin{array}{c}\text { Percent (\%) } \\
\text { efficiency of } \\
\text { movement trans- } \\
\text { complementation } \\
(\geq 5 \text { cells) }\end{array}$ \\
\end{tabular}

\begin{tabular}{|c|c|c|c|c|c|}
\hline $\begin{array}{l}\text { RFP-CaCV } \\
\text { NSm }\end{array}$ & 48 & 50 & 104 & 202 & 51 \\
\hline $\begin{array}{l}\text { RFP-CaCV } \\
\Delta \mathrm{NSm}\end{array}$ & 160 & 3 & 0 & 163 & 0 \\
\hline $\begin{array}{l}\text { RFP-TSWV } \\
\text { NSm }\end{array}$ & 52 & 46 & 55 & 153 & 36 \\
\hline $\begin{array}{l}\text { RFP-TSW } \\
\Delta \mathrm{NSm}\end{array}$ & 145 & 8 & 0 & 153 & 0 \\
\hline $\begin{array}{l}\text { TVCV P30- } \\
\text { RFP }\end{array}$ & 40 & 29 & 129 & 198 & 65 \\
\hline $\begin{array}{l}\text { TVCV } \triangle \text { P30- } \\
\text { RFP }\end{array}$ & 144 & 7 & 0 & 151 & 0 \\
\hline $\begin{array}{l}\text { Empty RFP- } \\
\text { vector }\end{array}$ & 146 & 8 & 0 & 154 & 0 \\
\hline
\end{tabular}

For instance, TSWV N protein has been shown to traffic on the actin/ER network, a novel property of a plant virus capsid protein (Feng et al., 2013). Studies on groundnut bud necrosis virus (GBNV) unraveled a novel feature of tospovirus NSm, which remodels ER networks to form vesicles to facilitate viral movement (Singh and Savithri, 2015). CaCV is an emerging tospovirus which is serologically and phylogenetically distinct (belongs to a different clade) from TSWV (McMichael et al., 2002; Oliver and Whitfield, 2016). Molecular characteristics of CaCV are largely unknown. In this study, we investigated properties of $\mathrm{CaCV}$ structural and non-structural proteins in comparison to those of TSWV to gain a better understanding of their involvement in the tospovirus infection cycle. We determined intracellular localizations and interactions of $\mathrm{CaCV}$ proteins in living plant cells and characterized the functions of the two non-structural proteins.

Tospoviruses studied so far are known to replicate in the cytoplasm of infected host plant cells (Poelwijk et al., 1995; Goldbach and Peters, 1996). Our data regarding CaCV protein intracellular localization and interactions provide evidence that $\mathrm{CaCV}$ also replicates in the cytoplasm. $\mathrm{CaCV}$ structural (N, Gc, Gn) and non-structural (NSs, NSm) proteins accumulated in the cytoplasm when transiently overexpressed. Cytoplasmic localization of viral proteins is common among tospoviruses (Lacorte et al., 2007; Kormelink et al., 2011; Dietzgen et al., 2012; Leastro et al., 2015; Tripathi et al., 2015a) and $\mathrm{CaCV}$ is no exception. We observed comparable intracellular localization patterns of $\mathrm{CaCV}$ proteins in the susceptible host plants $N$. benthamiana and capsicum, suggesting that protein localization may be independent of the host plant species. N protein localization showed aggregates abundantly dispersed in the cell periphery and in the perinuclear region in association with ER. As a structural protein that binds to and protects viral genomic RNA (Ie, 1971; Li et al., 2014), it is not surprising to see $\mathrm{N}$ protein aggregates in the cytoplasm of agroinfiltrated cells. $\mathrm{BiFC}$ showed that these aggregates were the result of $\mathrm{N}$ protein self-interaction. Self-interaction of $\mathrm{N}$ protein has previously been reported for several tospoviruses (Figure 10) including TSWV, CaCV-AIT (Thailand), and INSV (Lacorte et al., 2007; Zilian and Maiss, 2011; Dietzgen et al., 2012) and more recently for, bean necrotic mosaic virus (BeNMV), chrysanthemum stem necrosis virus (CSNV), iris yellow spot virus (IYSV), and tomato chlorotic spot virus (TCSV) (Leastro et al., 2015; Tripathi et al., 2015a). It is likely that $\mathrm{CaCV} \mathrm{N}$ protein aggregates in association with ER are $\mathrm{N}$ protein inclusions that traffic along the ER and actin network as was shown for TSWV (Feng et al., 2013).

It has been shown previously that the final intracellular destination of TSWV glycoproteins is the Golgi complex where glycoproteins wrap around viral RNP complexes to form doubly enveloped virus particles (Kikkert et al., 1999). These virus particles are then fused with each other and with ER-derived membranes to form large intracellular vesicles that contain singly enveloped virus particles. Similarly, we assume that $\mathrm{CaCV} \mathrm{N}$ protein aggregates may associate with viral RNA to form RNP complexes and traffic to the Golgi complex. In support we have shown $\mathrm{N}$ protein self-interaction and $\mathrm{Gn}-\mathrm{N}$ interaction in the cytoplasm. Using fluorescence life-time imaging microscopy, Ribeiro et al. (2009) showed that TSWV Gc is retained in the ER, while Gn spread further to the Golgi when singly expressed in $N$. tabacum protoplasts. When these proteins were co-expressed, Gn was able to rescue Gc to co-migrate to the Golgi complex. Our transient expression experiments showed that $\mathrm{CaCV} \mathrm{Gn}$ appears to partially localize at Golgi, whereas Gc was not, when expressed singly. When $\mathrm{CaCV}$ Gc and Gn were co-expressed there was no detectable alteration of localization profiles of these proteins. Non-Golgi localization of glycoproteins has been previously reported for INSV using the same Golgi marker (Dietzgen et al., 2012). In addition to cytoplasmic accumulation, both $\mathrm{CaCV}$ glycoproteins were also localized in the nucleus. Gn nuclear localization has so far not been reported for any other tospovirus and its function in the nucleus requires further investigation. Nuclear localization of Gc has been observed for INSV (Dietzgen et al., 2012) and IYSV (Tripathi et al., 2015a). Observed partial nuclear localization of $\mathrm{CaCV}$ glycoproteins is supported by predicted canonical NLSs. However, the biological significance of this nuclear localization cannot be explained based on current experimental data.

Tomato spotted wilt virus moves from cell-to-cell as a RNP complex (Kormelink et al., 1994) and NSm facilitates this movement through direct interaction with $\mathrm{N}$ protein (Soellick et al., 2000). Interactions of NSm and N proteins have also been reported for several tospoviruses other than TSWV (Dietzgen et al., 2012; Leastro et al., 2015; Singh and Savithri, 2015; Tripathi et al., 2015a). Therefore, we expected that CaCV NSm might interact with cognate $\mathrm{N}$ protein. However, BiFC assays did not show such an interaction in either orientation in repeated experiments, despite NSm being expressed and showing selfinteraction. This may be due to steric hindrance or limited access to NSm N-terminus in the fusion protein as observed for 

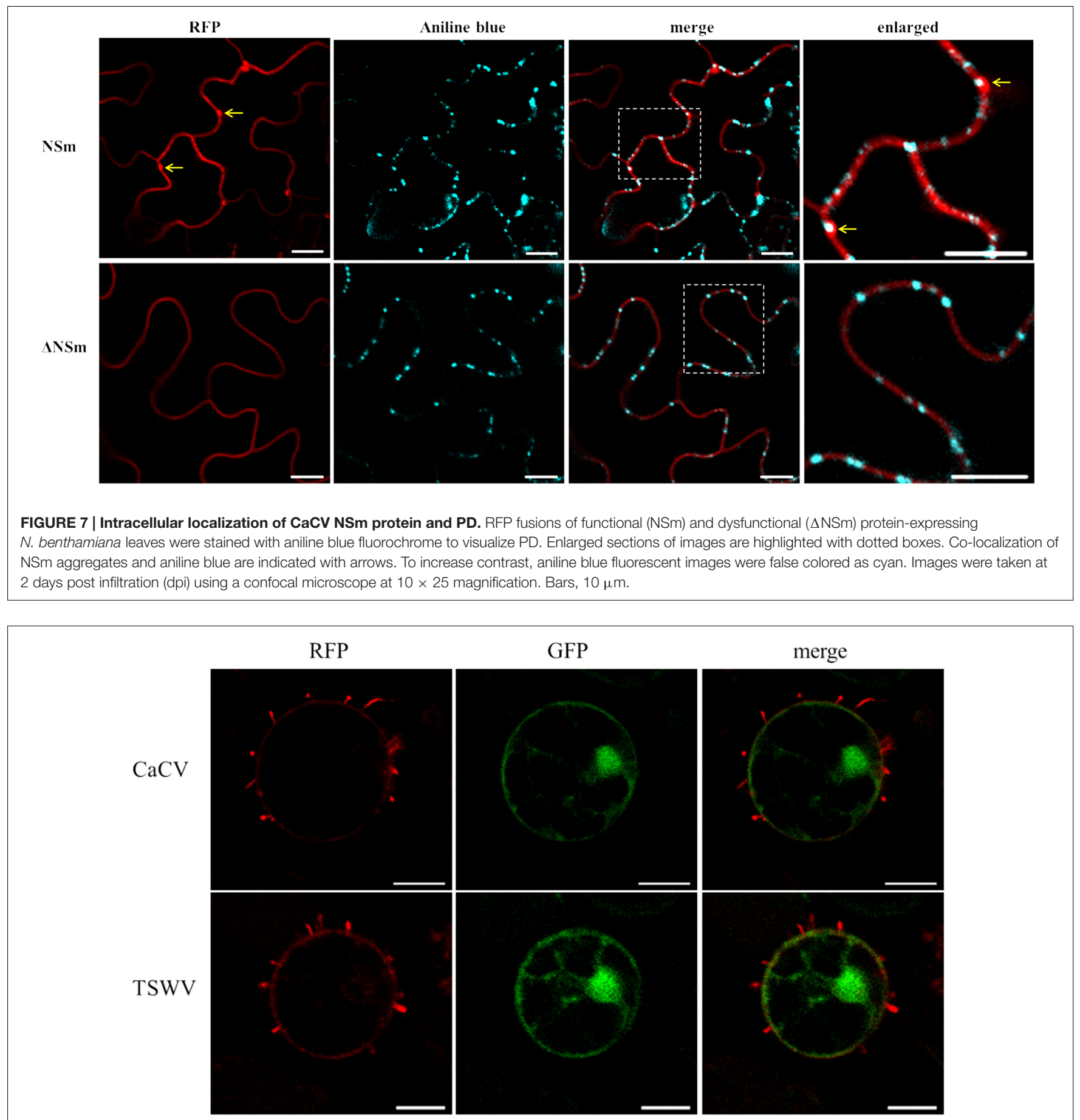

FIGURE 8 | Tubule-like structures protruding from protoplasts expressing tospovirus NSm proteins. Protoplasts were prepared $22 \mathrm{~h}$ after agroinfiltration from N. benthamiana leaves transiently expressing CaCV or TSWV NSm fused to RFP plus free GFP. Images were taken using a confocal microscope at $10 \times 40$ magnification after $5 \mathrm{~h}$ incubation of freshly prepared protoplasts at room temperature with constant light. Bars, $10 \mu \mathrm{m}$.

some other tospoviruses previously studied (Leastro et al., 2015; Singh and Savithri, 2015). These studies showed NSm-N dimer formation of BeNMV, GBNV, and TSWV was restricted to certain combinations of fluorescent protein pairs tested. Therefore, potential interactions of $\mathrm{CaCV} \mathrm{NSm}$ need to be confirmed using BiFC $\mathrm{N}$-series vectors (viral protein $\mathrm{N}$-terminus accessible due to fusion at C-terminus) and/or alternative protein-protein interaction assays. However, we cannot exclude other reasons for undetected interactions between $\mathrm{CaCV} \mathrm{NSm}$ and $\mathrm{N}$, such as involvement of host factors as bridges for viral protein 

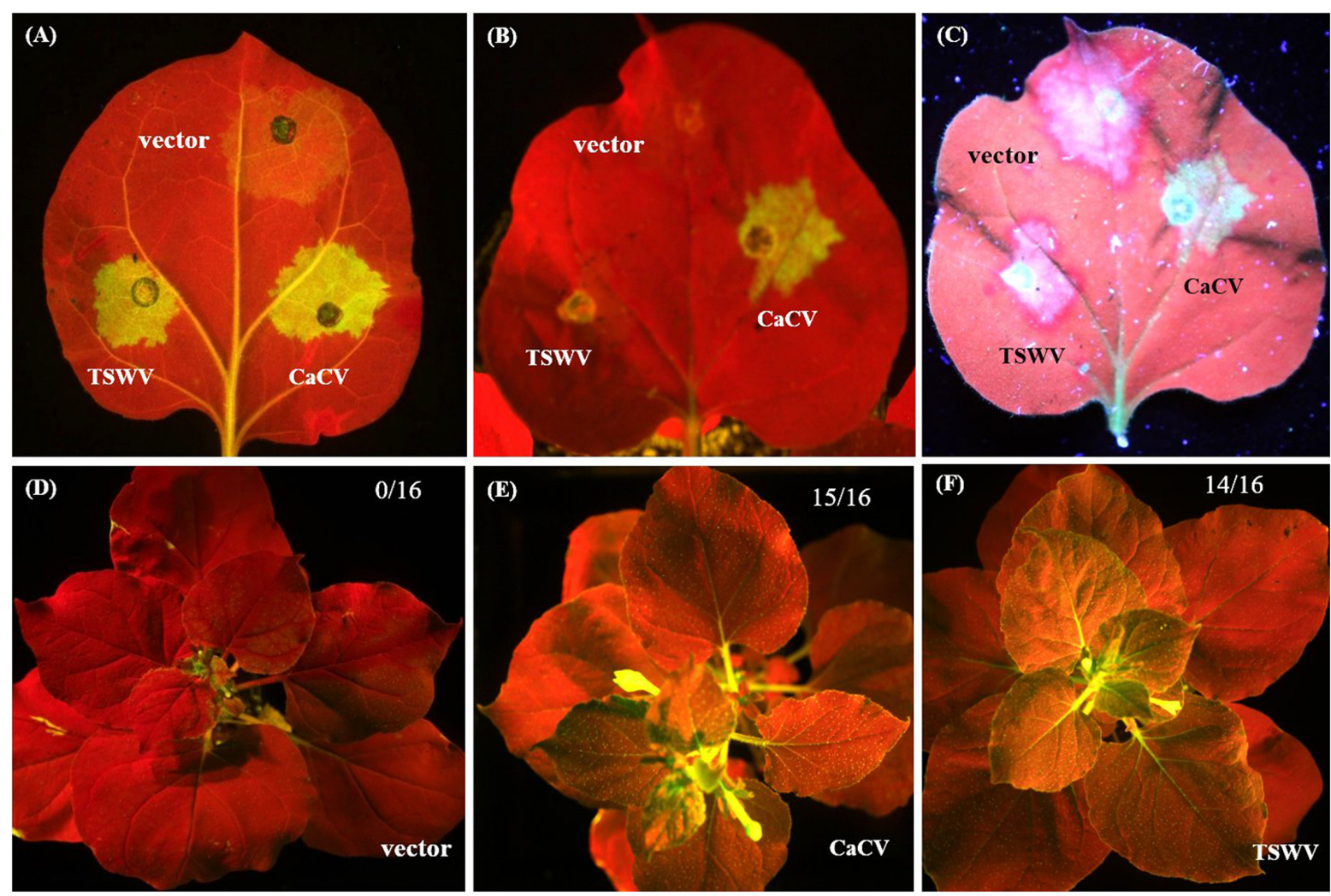

FIGURE 9 | Suppression of local and systemic gfp silencing by CaCV NSs protein. For local silencing assay, leaf patches of GFP-expressing N. benthamiana line 16c were agroinfiltrated with mGFP5-ER plus either CaCV NSs, TSWV NSs or empty vector and images were taken at day 3 (A) and day 7 (B). Formation of red halo surrounding infiltrated patches was viewed at $7 \mathrm{dpi}$ (C). For systemic silencing assay, line 16c plants were agroinfiltrated with mGFP5-ER plus either empty vector (D), CaCV NSs (E), or TSWV NSs (F) and images were taken at day 21. Number of GFP-expressing plants (silencing suppressed) per total number of plants tested are shown in the top right of each image. A Canon EOS camera containing a blue filter was used to take images (A,B,D-F) of plants exposed to blue light and image (C) was captured by exposing the same leaf shown in image (B) to long wavelength UV light using a Canon EOS camera equipped with a GFP filter.

interactions, like At-4/1 interactor of TSWV NSm (Paape et al., 2006). Association of cellular factors mediating connections between viral proteins that lead to cell-to-cell movement has also been described for plant rhabdoviruses (Min et al., 2010; Mann et al., 2016).

Recent studies have provided evidence for novel routes of intra- and intercellular trafficking of tospoviruses. Feng et al. (2013) showed cellular actin/ER membrane transport networks are involved in intracellular movement of TSWV N inclusions and ER network is involved in intercellular translocation of $\mathrm{NSm}$ and virus replication complexes where host factors are likely to play an important role (Feng et al., 2016). On the other hand, Singh and Savithri (2015) described vesicle-mediated intracellular transport of GBNV NSm. GBNV NSm directly interacts with ER membranes via a coiled-coil domain at the C-terminus, which remodels ER network to form vesicles that translocate NSm to PD. This property of GBNV NSm implies existence of potential alternate movement pathways for tospoviruses other than tubule formation. Furthermore, previous reports have shown that PD localization of NSm is apparently not a property shared by all tospoviruses. INSV and IYSV NSm did not have punctate distribution on the cell periphery suggesting these proteins do not form visible aggregates at PD (Dietzgen et al., 2012; Tripathi et al., 2015a). Taken together, localization and interaction profiles of tospovirus NSm proteins studied so far indicate potentially different strategies for intracellular trafficking, PD localization, and cell-to-cell movement (Paape et al., 2006; Dietzgen et al., 2012; Leastro et al., 2015, 2017; Singh and Savithri, 2015; Tripathi et al., 2015b; Feng et al., 2016). We speculate that different interacting host factors may be responsible for these differences.

We provide several lines of evidence to conclude that $\mathrm{CaCV}$ NSm represents the viral cell-to-cell movement protein. First, transiently expressed NSm localizes to and self-interacts on the cell periphery forming distinct punctate spots (Figures 1, 5). Second, these NSm spots appear to coincide with PD because they perfectly co-localize with callose deposits stained with aniline blue (Figure 4). Third, NSm self-interacts at PD to form tubular structures that are predicted to traverse PD. Tubule-like structures composed of RFP:NSm were seen protruding from the periphery of protoplasts (Figure 8). Fourth, NSm functionally trans-complements a movement-defective tobamovirus replicon (Figure 6). 


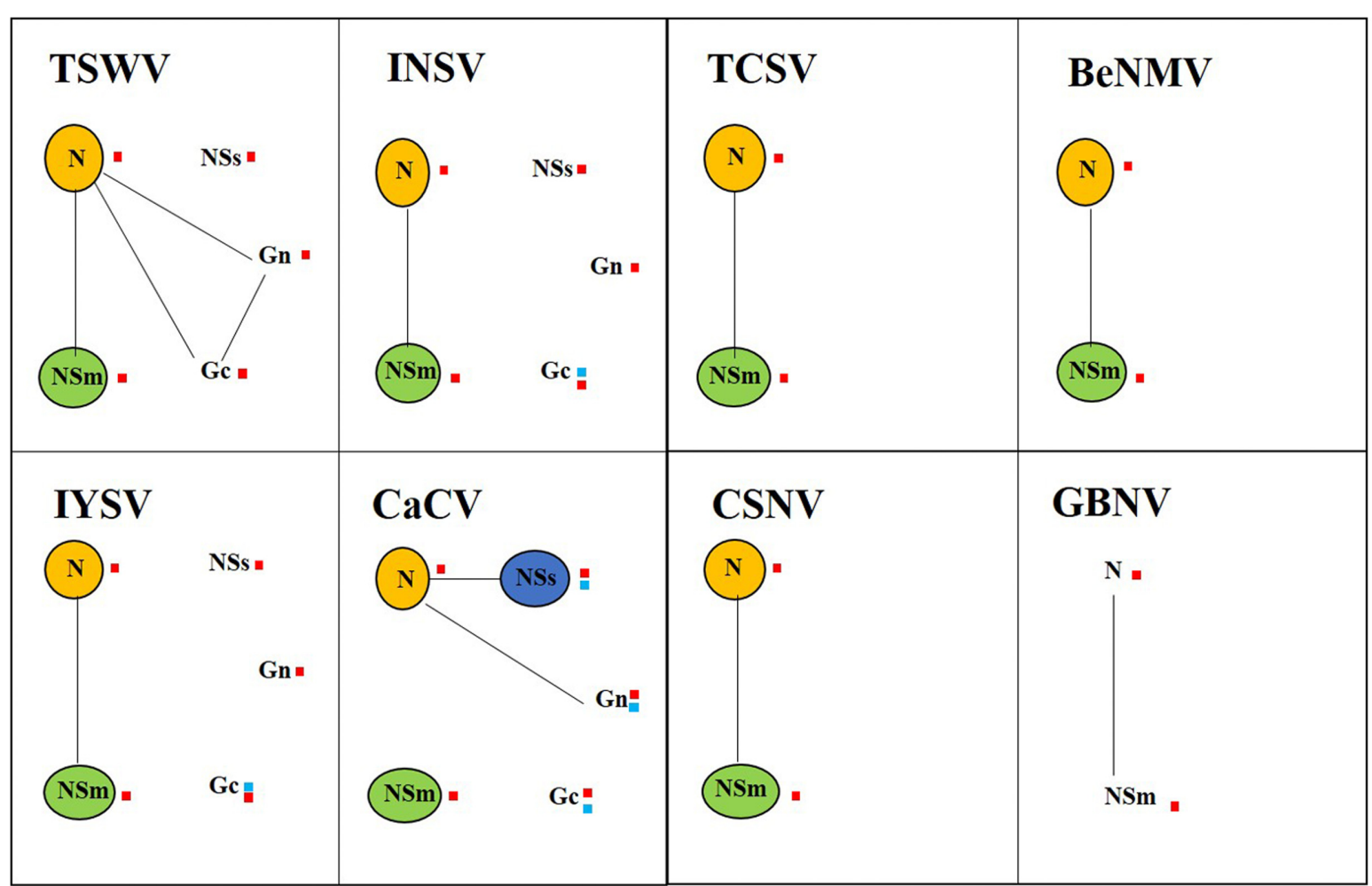

Cytoplasmic localization Homologous interaction

\section{Nuclear localization \\ - Heterologous interaction}

FIGURE 10 | Schematic map diagram of integrated localization and interaction data for tospovirus proteins determined in this study and compiled from the scientific literature for TSWV, impatiens necrotic spot virus (INSV), tomato chlorotic spot virus (TCSV), bean necrotic mosaic virus (BeNMV), iris yellow spot virus (IYSV), CaCV, chrysanthemum stem necrosis virus (CSNV), and groundnut bud necrosis virus (GBNV). Tospovirus proteins N, NSs, $\mathrm{NSm}, \mathrm{Gc}$, and Gn are indicated with homotypic interactions shown by circles and heterotypic interactions by connecting lines. Location of the interaction is indicated by red (cytoplasm) and/or blue (nucleus) squares next to the protein symbol.

NSm was first identified as functional cell-to-cell movement protein of TSWV (Lewandowski and Adkins, 2005). Here we demonstrated that $\mathrm{CaCV}$ NSm was able to trans-complement movement of a heterologous tobamovirus replicon. The efficiency of movement complementation in this assay by $\mathrm{CaCV}$ NSm was $42 \%$ greater than that of TSWV NSm, but $22 \%$ less than the homologous TVCV P30. Further, the pattern of cell-to-cell movement of movement-defective TVCV replicon complement by $\mathrm{CaCV}$ NSm was similar to that of TVCV P30 where radial clusters of cells are formed, but different to TSWV NSm which led to lateral movement. These observations support the notion that differences may exist between tospoviruses in intercellular transport of virus replication complexes or virions. We also investigated whether $\mathrm{D}$ to $\mathrm{A}$ mutation in the analogous $30 \mathrm{~K}$ specific $\mathrm{LxD} / \mathrm{N}_{50-70} \mathrm{G}$ motif in CaCV had an effect on cell-to-cell movement function and PD localization. Previously it was shown that TSWV $\mathrm{D}_{154}$ residue is essential for tubule formation and cell-to-cell movement ( $\mathrm{Li}$ et al., 2009). Mutation of this residue in TSWV and CaCV NSm interfered with cell-to-cell movement activity of these proteins. In addition, $\mathrm{CaCV}$ NSm mutant no longer formed punctate spots on the cell periphery and was not localized at $\mathrm{PD}$, suggesting $\mathrm{CaCV} \mathrm{D}_{155}$ residue is essential for PD localization and cell-to-cell movement. Collectively our results show that $\mathrm{CaCV}$ NSm functions as a cell-to-cell MP that localizes at PD, can form tubules and facilitates cell-to-cell movement.

We have provided live cell imaging evidence for a unique localization and interaction profile of CaCV NSs in the cell periphery and in the nucleus when individually transiently overexpressed following agroinfiltration. Previous similar studies of INSV and IYSV NSs showed exclusive cytoplasmic localization and no interactions with other viral proteins (Dietzgen et al., 2012; Tripathi et al., 2015a). On the other hand, CaCV NSs self-interaction exclusively occurred in the nucleus. A predicted canonical NLS appeared to provide additional support for partially nuclear localization of CaCV NSs, but a similar NLS score was obtained for TSWV NSs, which was shown to localize to the cytoplasm (Kormelink et al., 1991; Kikkert et al., 1997). On the other hand, overexpressed INSV GFP-NSs did not accumulate in the nucleus and has no predicted NLS 
(Dietzgen et al., 2012). The nuclear homotypic CaCV NSs interaction occurred infrequently in only five nuclei of 20 observed, whereas $>80 \%$ of nuclei accumulated NSs, suggesting that not all nuclear localized NSs proteins formed aggregates. Confocal microscopy of protoplasts expressing NSs detected by using a NSs MAb and immunofluorescence confirmed that $>90 \%$ of observed nuclei accumulated NSs. To validate that NSs has a partial nuclear localization also during virus infection, transmission electron microscopy in combination with immunogold labeling of leaf thin sections from $\mathrm{CaCV}$-infected plants should be done in future experiments. In the absence of a known nuclear export signal and partial accumulation in the cytoplasm, we speculate that NSs may shuttle between nucleus and cytoplasm through interacting with unknown host protein/s similar to the way that tombusvirus P19 partially translocates to the nucleus using ALY proteins (Canto et al., 2006). Furthermore, unlike other tospoviruses, CaCV NSs was uniquely shown to interact with $\mathrm{N}$ protein in the cytoplasm, an unexpected observation that warrants future study.

Bunyavirus NSs RNA silencing suppressor activity has only been clearly demonstrated for topoviruses, while for animal-infecting bunyaviruses it is still being debated (Hedil and Kormelink, 2016). CaCV NSs, like other tospoviral NSs proteins (Takeda et al., 2002; Schnettler et al., 2010; Goswami et al., 2012), functions as a suppressor of RNA silencing as evidenced by suppression of sense GFP-induced gene silencing both locally and systemically. Our local silencing suppression data show that GFP fluorescence in leaf patches expressing $\mathrm{CaCV}$ NSs remained bright at $7 \mathrm{dpi}$, whereas GFP expression was silenced in patches expressing TSWV NSs and negative control patches. RNA silencing induced locally may spread from initially silenced cells to adjacent cells through cell-tocell movement of siRNA, which can be observed in leaves of $N$. benthamiana line $16 \mathrm{c}$ when exposed to UV light as a red halo surrounding the infiltrated patch (Himber et al., 2003). Wide red zones surrounding TSWV NSs and vector patches were visible at $7 \mathrm{dpi}$, while less pronounced red halo was observed surrounding the patch expressing CaCV NSs. This suggests that TSWV NSs does not appear to interfere with the short-distance spread of the silencing signal, while $\mathrm{CaCV}$ NSs appears to delay or interfere, but does not prevent the short-distance spread of the silencing signal. Examination of GFP-derived siRNAs may provide additional evidence for $\mathrm{CaCV}$ NSs effects on siRNA accumulation. Previously, NSs of TSWV, GRSV, PoLRSV, and TYRV were shown to suppress long-distance systemic RNA silencing (Hedil et al., 2015; Margaria et al., 2016). These authors suggest that NSs may interfere with biogenesis of the systemic silencing signal (secondary siRNAs). The same study showed that NSs mutants that lacked local silencing suppression activity were still able to suppress systemic silencing, suggesting that NSs may exclusively target a step essential for systemic silencing. In the case of $\mathrm{CaCV}$ NSs, it is unknown if there is a correlation between NSs nuclear localization and its suppression of silencing activity or viral pathogenicity, and this warrants future research.

Integrated localization and interaction data or interactomes of tospoviruses studied so far show both shared and distinct properties of viral proteins (Figure 10) that may ultimately facilitate virus multiplication and spread in the host plant. Furthermore, these data hint at the complex nature of viral-viral and probably viral-host protein interactions. In conclusion, the present study demonstrates that compared to other tospoviruses, $\mathrm{CaCV}$ proteins have both conserved and unique properties in terms of in planta localization, protein-protein interactions, and protein functions which likely effect viral multiplication and movement in host plants.

\section{AUTHOR CONTRIBUTIONS}

SWG and RD conceived and designed the experiments; SWG performed the experiments; SWG and RD analyzed the data; RD contributed reagents/materials/analysis tools; SWG and RD wrote the paper.

\section{FUNDING}

This research was jointly supported by the Queensland Department of Agriculture and Fisheries and the University of Queensland through the Queensland Alliance for Agriculture and Food Innovation. SWG was supported by a 'Faculty for the Future' Fellowship from the Schlumberger Foundation, The Netherlands.

\section{ACKNOWLEDGMENTS}

We are indebted to Michael M. Goodin (University of Kentucky) for pSITE plant expression vectors, $N$. benthamiana fluorescent marker lines and expert technical advice. We thank Denis Persley (Department of Agriculture and Fisheries Queensland) for CaCV and TSWV isolates and sharing his deep knowledge of tospoviruses, Kerry Vinall (University of Queensland) for expert confocal microscope advice, Richard Kormelink (Wageningen University) for critical discussions and advice on protoplast isolation, Andreas Nebenführ (University of Tennessee) for plant organelle marker plasmids, and Shy-Dong Yeh (National Chung Hsing University, Taiwan) for NSs monoclonal antibody.

\section{SUPPLEMENTARY MATERIAL}

The Supplementary Material for this article can be found online at: http://journal.frontiersin.org/article/10.3389/fmicb. 2017.00612/full\#supplementary-material 


\section{REFERENCES}

Adkins, S., Choi, T.-J., Israel, B. A., Bandla, M. D., Richmond, K. E., Schultz, K. T., et al. (1996). Baculovirus expression and processing of tomato spotted wilt tospovirus glycoproteins. Mol. Plant Pathol. 86, 849-855. doi: 10.1094/phyto86-849

Canto, T., Uhrig, J. F., Swanson, M., Wright, K. M., and MacFarlane, S. A. (2006). Translocation of tomato bushy stunt virus P19 protein into the nucleus by ALY proteins compromises its silencing suppressor activity. J. Virol. 80, 9064-9072. doi: 10.1128/JVI.00953-06

Chakrabarty, R., Banerjee, R., Chung, S.-M., Farman, M., Citovsky, V., Hogenhout, S. A., et al. (2007). pSITE vectors for stable integration or transient expression of autofluorescent protein fusions in plants: probing Nicotiana benthamiana-virus interactions. Mol. Plant Microbe Interact. 20, 740-750. doi: 10.1094/MPMI-207-0740

Chen, C., Huang, C., Chen, T., Yeh, S., Cheng, Y., Hsu, H., et al. (2007). First report of capsicum chlorosis virus causing yellow stripes on calla lilies in Taiwan. Plant Dis. 91, 1201-1201. doi: 10.1094/PDIS-91-9-1201C

Chen, K., Xu, Z., Yan, L., and Wang, G. (2007). Characterization of a new strain of capsicum chlorosis virus from peanut (Arachis hypogaea L.) in China. J. Phytopthol. 155, 178-181. doi: 10.1111/j.1439-0434.2007.01217.x

Chen, T.-C., Huang, C.-W., Kuo, Y.-W., Liu, F.-L., Yuan, C.-H., Hsu, H.-T., et al. (2006). Identification of common epitopes on a conserved region of NSs proteins among tospoviruses of watermelon silver mottle virus serogroup. Phytopathology 96, 1296-1304. doi: 10.1094/PHYTO-96-1296

de Haan, P., Kormelink, R., de Oliveira Resende, R., Van Poelwijk, F., Peters, D., and Goldbach, R. (1991). Tomato spotted wilt virus L RNA encodes a putative RNA polymerase. J. Gen. Virol. 72, 2207-2216. doi: 10.1099/0022-1317-729-2207

de Haan, P., Wagemakers, L., Peters, D., and Goldbach, R. (1990). The S RNA segment of tomato spotted wilt virus has an ambisense character. J. Gen. Virol. 71, 1001-1007. doi: 10.1099/0022-1317-71-5-1001

Dietzgen, R. G., Martin, K. M., Anderson, G., and Goodin, M. M. (2012). In planta localization and interactions of impatiens necrotic spot tospovirus proteins. J. Gen. Virol. 93, 2490-2495. doi: 10.1099/vir.0.042515-0

Feng, Z., Chen, X., Bao, Y., Dong, J., Zhang, Z., and Tao, X. (2013). Nucleocapsid of tomato spotted wilt tospovirus forms mobile particles that traffic on an actin/endoplasmic reticulum network driven by myosin XI-K. New Phytol. 200, 1212-1224. doi: 10.1111/nph.12447

Feng, Z., Xue, F., Xu, M., Chen, X., Zhao, W., Garcia-Murria, M. J., et al. (2016). The ER-membrane transport system is critical for intercellular trafficking of the NSm movement protein and tomato spotted wilt tospovirus. PLoS Pathog. 12:e1005443. doi: 10.1371/journal.ppat.1005443

Giritch, A., Marillonnet, S., Engler, C., van Eldik, G., Botterman, J., Klimyuk, V., et al. (2006). Rapid high-yield expression of full-size IgG antibodies in plants coinfected with noncompeting viral vectors. Proc. Natl. Acad. Sci. U.S.A. 103, 14701-14706. doi: 10.1073/pnas.0606631103

Goldbach, R., and Peters, D. (1996). "Molecular and biological aspects of tospoviruses," in The Bunyaviridae, ed. R. M. Elliott (New York, NY: Springer), 129-157.

Goswami, S., Sahana, N., Pandey, V., Doblas, P., Jain, R. K., Palukaitis, P., et al. (2012). Interference in plant defense and development by non-structural protein NSs of groundnut bud necrosis virus. Virus Res. 163, 368-373. doi: 10.1016/j.virusres.2011.08.016

Hedil, M., and Kormelink, R. (2016). Viral RNA silencing suppression: the enigma of bunyavirus NSs proteins. Viruses 8:208. doi: 10.3390/v8070208

Hedil, M., Sterken, M. G., de Ronde, D., Lohuis, D., and Kormelink, R. (2015). Analysis of tospovirus NSs proteins in suppression of systemic silencing. PLoS ONE 10:e0134517. doi: 10.1371/journal.pone.0134517

Hibi, T., Rezelman, G., and Van Kammen, A. (1975). Infection of cowpea mesophyll protoplasts with cowpea mosaic virus. Virology 64, 308-318. doi: 10.1016/0042-6822(75)90107-5

Himber, C., Dunoyer, P., Moissiard, G., Ritzenthaler, C., and Voinnet, O. (2003). Transitivity-dependent and-independent cell-to-cell movement of RNA silencing. EMBO J. 22, 4523-4533. doi: 10.1093/emboj/cdg431

Ie, T. (1971). Electron microscopy of developmental stages of tomato spotted wilt virus in plant cells. Virology 43, 468-479. doi: 10.1016/0042-6822(71) 90318-7
Johansen, L. K., and Carrington, J. C. (2001). Silencing on the spot. Induction and suppression of RNA silencing in the Agrobacterium-mediated transient expression system. Plant Physiol. 126, 930-938. doi: 10.1104/pp.126.3.930

Kikkert, M., Van Lent, J., Storms, M., Bodegom, P., Kormelink, R., and Goldbach, R. (1999). Tomato spotted wilt virus particle morphogenesis in plant cells. J. Virol. 73, 2288-2297.

Kikkert, M., van Poelwijk, F., Storms, M., Kassies, W., Bloksma, H., van Lent, J., et al. (1997). A protoplast system for studying tomato spotted wilt virus infection. J. Gen. Virol. 78, 1755-1763. doi: 10.1099/0022-1317-78-7-1755

Kikkert, M., Verschoor, A., Kormelink, R., Rottier, P., and Goldbach, R. (2001). Tomato spotted wilt virus glycoproteins exhibit trafficking and localization signals that are functional in mammalian cells. J. Virol. 75, 1004-1012. doi: 10.1128/JVI.75.2.1004-1012.2001

Knierim, D., Blawid, R., and Maiss, E. (2006). The complete nucleotide sequence of a capsicum chlorosis virus isolate from Lycopersicum esculentum in Thailand. Arch. Virol. 151, 1761-1782. doi: 10.1007/s00705-006-0749-4

Kormelink, R. (2011). “The molecular biology of tospoviruses and resistance strategies," in Bunyaviridae: Molecular and Cellular Biology, eds A. Plyusnin and R. Elliott (Norwich: Caister Academic Press), 163-191.

Kormelink, R., Kitajima, E. W., De Haan, P., Zuidema, D., Peters, D., and Goldbach, R. (1991). The nonstructural protein (NSs) encoded by the ambisense S RNA segment of tomato spotted wilt virus is associated with fibrous structures in infected plant cells. Virology 181, 459-468. doi: 10.1016/00426822(91)90878-F

Kormelink, R., de Haan, P., Meurs, C., Peters, D., and Goldbach, R. (1992). The nucleotide sequence of the M RNA segment of tomato spotted wilt virus, a bunyavirus with two ambisense RNA segments. J. Gen. Virol. 73, 2795-2804. doi: 10.1099/0022-1317-73-11-2795

Kormelink, R., Garcia, M. L., Goodin, M., Sasaya, T., and Haenni, A.-L. (2011). Negative-strand RNA viruses: the plant-infecting counterparts. Virus Res. 162, 184-202. doi: 10.1016/j.virusres.2011.09.028

Kormelink, R., Storms, M., Van Lent, J., Peters, D., and Goldbach, R. (1994). Expression and subcellular location of the NSm protein of tomato spotted wilt virus (TSWV), a putative viral movement protein. Virology 200, 56-65. doi: 10.1006/viro.1994.1162

Kosugi, S., Hasebe, M., Tomita, M., and Yanagawa, H. (2009). Systematic identification of cell cycle-dependent yeast nucleocytoplasmic shuttling proteins by prediction of composite motifs. Proc. Natl. Acad. Sci. U.S.A. 106, 10171-10176. doi: 10.1073/pnas.0900604106

Kunkalikar, S., Poojari, S., Rajagopalan, P., Zehr, U. B., Naidu, R. A., and Kankanallu, R. S. (2007). First report of capsicum chlorosis virus in tomato in India. Plant Health Prog. doi: 10.1094/PHP-2007-1204-01-BR

La Cour, T., Kiemer, L., Mølgaard, A., Gupta, R., Skriver, K., and Brunak, S. (2004). Analysis and prediction of leucine-rich nuclear export signals. Protein Eng. Des. Sel. 17, 527-536. doi: 10.1093/protein/gzh062

Lacorte, C., Ribeiro, S. G., Lohuis, D., Goldbach, R., and Prins, M. (2007). The nucleoprotein of tomato spotted wilt virus as protein tag for easy purification and enhanced production of recombinant proteins in plants. Protein Expr. Purif. 55, 17-22. doi: 10.1016/j.pep.2007.03.014

Laemmli, U. K. (1970). Cleavage of structural proteins during the assembly of the head of bacteriophage T4. Nature 227, 680-685. doi: 10.1038/227680a0

Leastro, M., Pallás, V., Resende, R., and Sánchez-Navarro, J. (2015). The movement proteins (NSm) of distinct tospoviruses peripherally associate with cellular membranes and interact with homologous and heterologous NSm and nucleocapsid proteins. Virology 478, 39-49. doi: 10.1016/j.virol.2015.01.031

Leastro, M. O., Pallás, V., Resende, R. O., and Sánchez-Navarro, J. A. (2017). The functional analysis of distinct tospovirus movement proteins (NSm) reveals different capabilities in tubule formation, cell-to-cell and systemic virus movement among the tospovirus species. Virus Res. 227, 57-68. doi: 10.1016/j. virusres.2016.09.023

Lewandowski, D. J., and Adkins, S. (2005). The tubule-forming NSm protein from tomato spotted wilt virus complements cell-to-cell and long-distance movement of tobacco mosaic virus hybrids. Virology 342, 26-37. doi: 10.1016/j. virol.2005.06.050

Li, J., Feng, Z., Wu, J., Huang, Y., Lu, G., Zhu, M., et al. (2014). Structure and function analysis of nucleocapsid protein of tomato spotted wilt tospovirus interacting with RNA using homology modeling. J. Biol. Chem. 290, 3950-3961. doi: $10.1074 /$ jbc.M114.604678 
Li, W., Lewandowski, D. J., Hilf, M. E., and Adkins, S. (2009). Identification of domains of the tomato spotted wilt virus NSm protein involved in tubule formation, movement and symptomatology. Virology 390, 110-121. doi: $10.1016 /$ j.virol.2009.04.027

Mann, K. S., Bejerman, N., Johnson, K. N., and Dietzgen, R. G. (2016). Cytorhabdovirus P3 genes encode 30K-like cell-to-cell movement proteins. Virology 489, 20-33. doi: 10.1016/j.virol.2015.11.028

Margaria, P., Miozzi, L., Ciuffo, M., Rosa, C., Axtell, M. J., Pappu, H. R., et al. (2016). Comparison of small RNA profiles in Nicotiana benthamiana and Solanum lycopersicum infected by polygonum ringspot tospovirus reveals hostspecific responses to viral infection. Virus Res. 211, 38-45. doi: 10.1016/j. virusres.2015.09.019

Marillonnet, S., Giritch, A., Gils, M., Kandzia, R., Klimyuk, V., and Gleba, Y. (2004). In planta engineering of viral RNA replicons: efficient assembly by recombination of DNA modules delivered by Agrobacterium. Proc. Natl. Acad. Sci. U.S.A. 101, 6852-6857. doi: 10.1073/pnas.0400149101

Marillonnet, S., Thoeringer, C., Kandzia, R., Klimyuk, V., and Gleba, Y. (2005). Systemic Agrobacterium tumefaciens-mediated transfection of viral replicons for efficient transient expression in plants. Nat. Biotechnol. 23, 718-723. doi: $10.1038 /$ nbt1094

Martin, K., Kopperud, K., Chakrabarty, R., Banerjee, R., Brooks, R., and Goodin, M. M. (2009). Transient expression in Nicotiana benthamiana fluorescent marker lines provides enhanced definition of protein localization, movement and interactions in planta. Plant J. 59, 150-162. doi: 10.1111/j.1365-313X.2009. 03850.x

McDonnell, A. V., Jiang, T., Keating, A. E., and Berger, B. (2006). Paircoil2: improved prediction of coiled coils from sequence. Bioinformatics 22, 356-358.

McMichael, L. A., Persley, D. M., and Thomas, J. E. (2002). A new tospovirus serogroup IV species infecting capsicum and tomato in Queensland, Australia. Australas. Plant Pathol. 31, 231-239. doi: 10.1071/AP02016

Min, B.-E., Martin, K., Wang, R., Tafelmeyer, P., Bridges, M., and Goodin, M. (2010). A host-factor interaction and localization map for a plant-adapted rhabdovirus implicates cytoplasm-tethered transcription activators in cell-tocell movement. Mol. Plant Microbe Interact. 23, 1420-1432. doi: 10.1094/ MPMI-04-10-0097

Nelson, B. K., Cai, X., and Nebenführ, A. (2007). A multicolored set of in vivo organelle markers for co-localization studies in Arabidopsis and other plants. Plant J. 51, 1126-1136. doi: 10.1111/j.1365-313X.2007.03212.x

Oliver, J., and Whitfield, A. (2016). The genus Tospovirus: emerging bunyaviruses that threaten food security. Annu. Rev. Virol. 3, 101-124. doi: 10.1146/annurevvirology-100114-055036

Paape, M., Solovyev, A. G., Erokhina, T. N., Minina, E. A., Schepetilnikov, M. V., Lesemann, D.-E., et al. (2006). At-4/1, an interactor of the tomato spotted wilt virus movement protein, belongs to a new family of plant proteins capable of directed intra-and intercellular trafficking. Mol. Plant Microbe Interact. 19, 874-883. doi: 10.1094/MPMI-19-0874

Pei, J., and Grishin, N. V. (2014). "PROMALS3D: multiple protein sequence alignment enhanced with evolutionary and three-dimensional structural information," in Multiple Sequence Alignment Methods, ed. D. J. Russell (Totowa, NJ: Humana Press), 263-271.

Plyusnin, A., Beaty, B., Elliott, R., Goldbach, R., Kormelink, R., Lundkvist, Å., et al. (2011). "Family Bunyaviridae," in Proceedings of the Virus Taxonomy: IXth Report of the International Committee on Taxonomy of Viruses, eds A. King, M. Adams, and E. Lefkowitz (San Diego, CA: Elsevier), 737-741.

Poelwijk, F. V., Haan, P. D., Kikkert, M., Prins, M., Kormelink, R., Storms, M., et al. (1995). Replication and expression of the tospoviral genome. Acta Hortic. 431, 201-208.

Ribeiro, D., Borst, J. W., Goldbach, R., and Kormelink, R. (2009). Tomato spotted wilt virus nucleocapsid protein interacts with both viral glycoproteins $\mathrm{Gn}$ and Gc in planta. Virology 383, 121-130. doi: 10.1016/j.virol.2008.09.028

Ribeiro, D., Foresti, O., Denecke, J., Wellink, J., Goldbach, R., and Kormelink, R. J. (2008). Tomato spotted wilt virus glycoproteins induce the formation of endoplasmic reticulum-and Golgi-derived pleomorphic membrane structures in plant cells. J. Gen. Virol. 89, 1811-1818. doi: 10.1099/vir.0.2008/001164-0

Ruiz, M. T., Voinnet, O., and Baulcombe, D. C. (1998). Initiation and maintenance of virus-induced gene silencing. Plant Cell 10, 937-946. doi: 10.1105/tpc.10. 6.937

Schneider, C. A., Rasband, W. S., and Eliceiri, K. W. (2012). NIH image to ImageJ: 25 years of image analysis. Nat. Methods 9, 671-675. doi: 10.1038/nmeth.2089
Schnettler, E., Hemmes, H., Huismann, R., Goldbach, R., Prins, M., and Kormelink, R. (2010). Diverging affinity of tospovirus RNA silencing suppressor proteins, NSs, for various RNA duplex molecules. J. Virol. 84, 11542-11554. doi: 10.1128/JVI.00595-10

Singh, P., and Savithri, H. (2015). GBNV encoded movement protein (NSm) remodels ER network via C-terminal coiled coil domain. Virology 482, 133-146. doi: 10.1016/j.virol.2015.01.030

Snippe, M., Borst, J. W., Goldbach, R., and Kormelink, R. (2005). The use of fluorescence microscopy to visualise homotypic interactions of tomato spotted wilt virus nucleocapsid protein in living cells. J. Virol. Methods 125, 15-22. doi: 10.1016/j.jviromet.2004.11.028

Snippe, M., Smeenk, L., Goldbach, R., and Kormelink, R. (2007a). The cytoplasmic domain of tomato spotted wilt virus Gn glycoprotein is required for Golgi localisation and interaction with Gc. Virology 363, 272-279. doi: 10.1016/j.virol. 2006.12.038

Snippe, M., Willem Borst, J., Goldbach, R., and Kormelink, R. (2007b). Tomato spotted wilt virus $\mathrm{Gc}$ and $\mathrm{N}$ proteins interact in vivo. Virology 357, 115-123. doi: 10.1016/j.virol.2006.06.037

Soellick, T.-R., Uhrig, J., Bucher, G., Kellmann, J.-W., and Schreier, P. (2000). The movement protein NSm of tomato spotted wilt tospovirus (TSWV): RNA binding, interaction with the TSWV N protein, and identification of interacting plant proteins. Proc. Natl. Acad. Sci. U.S.A. 97, 2373-2378. doi: 10.1073/pnas. 030548397

Storms, M. M., Kormelink, R., Peters, D., van Lent, J. W., and Goldbach, R. W. (1995). The nonstructural NSm protein of tomato spotted wilt virus induces tubular structures in plant and insect cells. Virology 214, 485-493. doi: 10.1006/ viro.1995.0059

Takeda, A., Sugiyama, K., Nagano, H., Mori, M., Kaido, M., Mise, K., et al. (2002). Identification of a novel RNA silencing suppressor, NSs protein of tomato spotted wilt virus. FEBS Lett. 532, 75-79. doi: 10.1016/S0014-5793(02)03632-3

Tripathi, D., Raikhy, G., Goodin, M. M., Dietzgen, R. G., and Pappu, H. R. (2015a). In vivo localization of iris yellow spot tospovirus (Bunyaviridae)encoded proteins and identification of interacting regions of nucleocapsid and movement proteins. PLOS ONE 10:e0118973. doi: 10.1371/journal.pone. 0118973

Tripathi, D., Raikhy, G., and Pappu, H. R. (2015b). Movement and nucleocapsid proteins coded by two tospovirus species interact through multiple binding regions in mixed infections. Virology 478, 137-147. doi: 10.1016/j.virol.2015. 01.009

Tsai, C.-W., Redinbaugh, M. G., Willie, K. J., Reed, S., Goodin, M., and Hogenhout, S. A. (2005). Complete genome sequence and in planta subcellular localization of maize fine streak virus proteins. J. Virol. 79, 5304-5314. doi: 10.1128/JVI.79. 9.5304-5314.2005

van Poelwuk, F., Boye, K., Oosterling, R., Peters, D., and Goldbach, R. (1993). Detection of the L protein of tomato spotted wilt virus. Virology 197, 468-470. doi: 10.1006/viro.1993.1614

Widana Gamage, S., Persley, D. M., Higgins, C. M., and Dietzgen, R. G. (2015). First complete genome sequence of a capsicum chlorosis tospovirus isolate from Australia with an unusually large S RNA intergenic region. Arch. Virol. 160, 869-872. doi: 10.1007/s00705-014-2324-8

Zheng, Y.-X., Chen, C.-C., and Jan, F.-J. (2011). Complete nucleotide sequence of capsicum chlorosis virus isolated from Phalaenopsis orchid and the prediction of the unexplored genetic information of tospoviruses. Arch. Virol. 156, 421-432. doi: 10.1007/s00705-010-0874-y

Zilian, E., and Maiss, E. (2011). An optimized mRFP-based bimolecular fluorescence complementation system for the detection of protein-protein interactions in planta. J. Virol. Methods 174, 158-165. doi: 10.1016/j.jviromet. 2011.03.032

Conflict of Interest Statement: The authors declare that the research was conducted in the absence of any commercial or financial relationships that could be construed as a potential conflict of interest.

Copyright (C) 2017 Widana Gamage and Dietzgen. This is an open-access article distributed under the terms of the Creative Commons Attribution License (CC BY). The use, distribution or reproduction in other forums is permitted, provided the original author(s) or licensor are credited and that the original publication in this journal is cited, in accordance with accepted academic practice. No use, distribution or reproduction is permitted which does not comply with these terms. 